\title{
O Sistema Regional de Inovação Fluminense: características, desafios e potencialidades
}

\author{
Israel Sanches Marcellino ${ }^{1}$ \\ Vanessa de Lima Avanci ${ }^{2}$ \\ Jorge Britto ${ }^{3}$
}

\begin{abstract}
RESUMO
O atual momento vivido pela economia do Rio de Janeiro aponta um horizonte de crescimento econômico baseado em investimentos de grande porte que podem trazer importantes mudanças para a estrutura produtiva. Os desafios desse momento envolvem, portanto, avaliar a estrutura produtiva e tecnológica e as limitações que devem ser superadas para que a mudança estrutural seja acompanhada de crescimento sustentado. O recorte de sistemas regionais de inovação (SRIs) entende a inovação como um fenômeno sistêmico, que ocorre no interior de um ambiente econômico e sócio-institucional permeado de especificidades geograficamente determinadas. A partir desse recorte analítico, o artigo procura fornecer evidências preliminares a respeito do SRI fluminense. Especificamente, procura-se analisar, em linhas gerais, as condições de financiamento às atividades de ciência, tecnologia e inovação $(\mathrm{C}, \mathrm{T} \& \mathrm{I})$, as características da base de competências presentes no estado do Rio de Janeiro e indicadores do desempenho inovativo da região. As evidências analisadas indicam que o SRI fluminense apresenta deficiências na conversão de recursos humanos e financeiros em uma performance de atividade inovativa compatível. A conclusão resultante deste trabalho, a ser investigada em pesquisas futuras, é de que o SRI do Rio de Janeiro tem um elo fraco nas interações entre as atividades de geração de conhecimento e aquelas associadas à exploração de conhecimento economicamente útil.
\end{abstract}

Palavras-chave: economia fluminense; governança; inovação; política científicotecnológica; sistemas regionais de inovação

\footnotetext{
${ }^{1}$ Economista graduado pela UFRJ, mestrando pelo PPGE/UFF.

${ }^{2}$ Economista graduada pela UFES, mestranda pelo PPGE/UFF.

${ }^{3}$ Professor Associado do Departamento de Economia da UFF.
} 


\begin{abstract}
The economy of Rio de Janeiro has faced $n$ horizon of economic growth based on the impact of large investment that can bring important changes over the productive structure. In this context, one of the main challenges refers to the need of an evaluation the productive and technological structure, in order to identify the limitations that must be overcome to allow these structural changes to be accompanied by a process of sustained growth. The regional innovation systems (RISs) frame work conceives innovation as a systemic phenomenon embedded in an economic and socio-institutional environment with geographic and territorial specificities. From this theoretical basis, the study aims to provide preliminary evidence regarding the Rio de Janeiro RIS. Specifically, the study stresses how science, technology and innovation (S,T\&I) activities have been funded in recent years, the competence base present in the state of Rio de Janeiro and regional indicators related to the innovative performance. The data and evidence analyzed points that the Rio de Janeiro RIS still presents deficiencies related to the conversion of human and financial resources in a compatible innovative performance. The general conclusion, to be further investigated in future research, is that the Rio de Janeiro RIS has a weak link related to the interactions between the knowledge generation activities and the activities involved with the exploitation of economically useful knowledge.
\end{abstract}

Keywords: Rio de Janeiro economy; governance; innovation; scientific and technologic policy; regional innovation system

\title{
Introdução
}

O Rio de Janeiro abriga um expressivo conjunto de organizações e instituições voltadas à geração de conhecimento científico e tecnológico. Em parte isso ocorre pelo seu passado de capital nacional e seu legado materializado na presença de inúmeras instituições federais de peso, seja na esfera produtiva seja no campo da infraestrutura de ciência e tecnologia(C\&T). Porém, o processo de degradação da economia fluminense na segunda metade do século XX e o esvaziamento econômico colaboram para colocar em xeque o argumento de que uma significativa base de competências é suficiente para se avançar em termos de uma trajetória sustentável de inovação, crescimento e mudança estrutural.

O atual momento vivido pela economia do Rio de Janeiro aponta um horizonte de crescimento econômico proporcionado por investimentos de grande porte que podem trazer importantes mudanças para a estrutura produtiva. Neste contexto, é importante avaliar querumos a economia do estado pode tomar e quais são os riscos e desafios 
inerentes a esse processo. Especialmente, é preciso pensar em termos da geração de estímulos endógenos sustentados ao processo de desenvolvimento, principalmente face à perspectiva de uma gradual queda do fluxo de recursos investidos à medida que os projetos se consolidarem.

Uma das questões fundamentais a se considerar nesse debate refere-se ao papel da inovação para o fortalecimento de uma trajetória sustentável de desenvolvimento regional. De fato, desde que combinados com outras condições, como o encadeamento da estrutura produtiva, seus padrões de especialização e diversificação e as trajetórias tecnológicas em que se inserem seus principais setores, o fomento à inovação e o estímulo à transferência tecnológica na esfera regional são fatores relevantes. Estimulando-se a inovação e sua difusão dentro da região, as firmas localizadas no território fluminense podem aumentar o valor de sua produção ese tornar capazes de concorrer em outros mercados, como o nacional e o internacional.

Entendendo a inovação como um fenômeno sistêmico, que ocorre em um ambiente econômico e socioinstitucional marcado por especificidades territoriais, o recorte de sistemas regionais de inovação (SRIs) se mostra funcional para a discussão de alguns desafios importantes para o desenvolvimento fluminense. O objetivo do presente artigo, portanto, é contribuir para esse debate fornecendo evidências preliminares sobre a estrutura do SRI fluminense. Nesse sentido, procura-se analisar, em linhas gerais, as condições de financiamento às atividades de ciência, tecnologia e inovação (C,T\&I), as características da base de competências presentes no Estado do Rio de Janeiro e alguns indicadores da região em termos de esforços e performance inovativa.

O artigo estrutura-se em cinco seções, além desta Introdução. A primeira parte apresenta o referencial teórico de SRI, identificando a partir desse referencial, as principais dimensões desse sistema a serem investigadas nas seções subsequentes. A segunda seção busca compreender melhor a estrutura de financiamento às atividades de C,T\&I existente no Estado do Rio de Janeiro. A terceira seção aborda aspectos específicos relacionados à base de competências fluminense, compreendida como fator fundamental para a dinamização do sistema de inovação regional. A quarta seção discute aspectos relacionados ao desempenho inovativo recente da economia fluminense. Por fim, uma última seção desenvolve algumas considerações sobre os 
principais desafios para o fortalecimento do SRI fluminense como fator de dinamização do desenvolvimento regional.

\section{O marco teórico dos SRI e a noção de subsistemas: uma análise aplicada à realidade fluminense}

Inserido em dois debates distintos, o conceito de sistemas regionais de inovação, formalizado por Cooke (1992), dialoga tanto com a ciência regional quanto com as outras abordagens de sistemas de inovação. O contexto a partir do qual se estrutura esse programa de pesquisa reflete o reconhecimento das dificuldades enfrentadas pelas teorias tradicionais de economia regional - prévias à década de 1980 em fornecer explicações satisfatórias para a estagnação econômica de importantes regiões europeias e, consequentemente, para elaborar recomendações normativas. Ademais, reflete também a ascensão de teorias respaldadas no conceito genérico de "sistemas de inovação" e de temas relativos à relação entre competitividade e inovação no debate acadêmico e na agenda política europeia (Doloreux eParto, 2004;Arancegui, 2009 e Cooke, 2001).

De forma sucinta, um SRI pode ser entendido como um conjunto de agentes públicos e privados, instituições formais e outras organizações que, interagindo entre si, funcionam de forma a conduzir a geração, o uso e a disseminação do conhecimento (Doloreux, 2003; 2004; Doloreux e Parto, 2004;Doloreux et al., 2004). Dessa maneira, o sistema não se integra somente pelas firmas privadas, mas também inclui órgãos de pesquisa, instituições de financiamento e de governança, institutos de educação técnica e superior, policymakers e também os padrões socioculturais relativos à atividade inovativa incorporados ao contexto regional.

Com a intenção de fornecer uma concepção mais concreta e concisa de um SRI, podemos pensá-lo, também, como um esquema interativo de três subsistemas, conforme proposta na sistematização realizada por Tödtling e Trippl (2005) e Arancegui (2009). Conforme pode ser visto na Figura 1, os três subsistemas mencionados compreendem, por um lado, a geração e difusão de conhecimento, por outro, a utilização desse conhecimento pelo setor produtivo e, por fim, um subsistema específico à formulação e implementação de políticas no plano regional. 
Figura 1.Composição de um Sistema Regional de Inovação

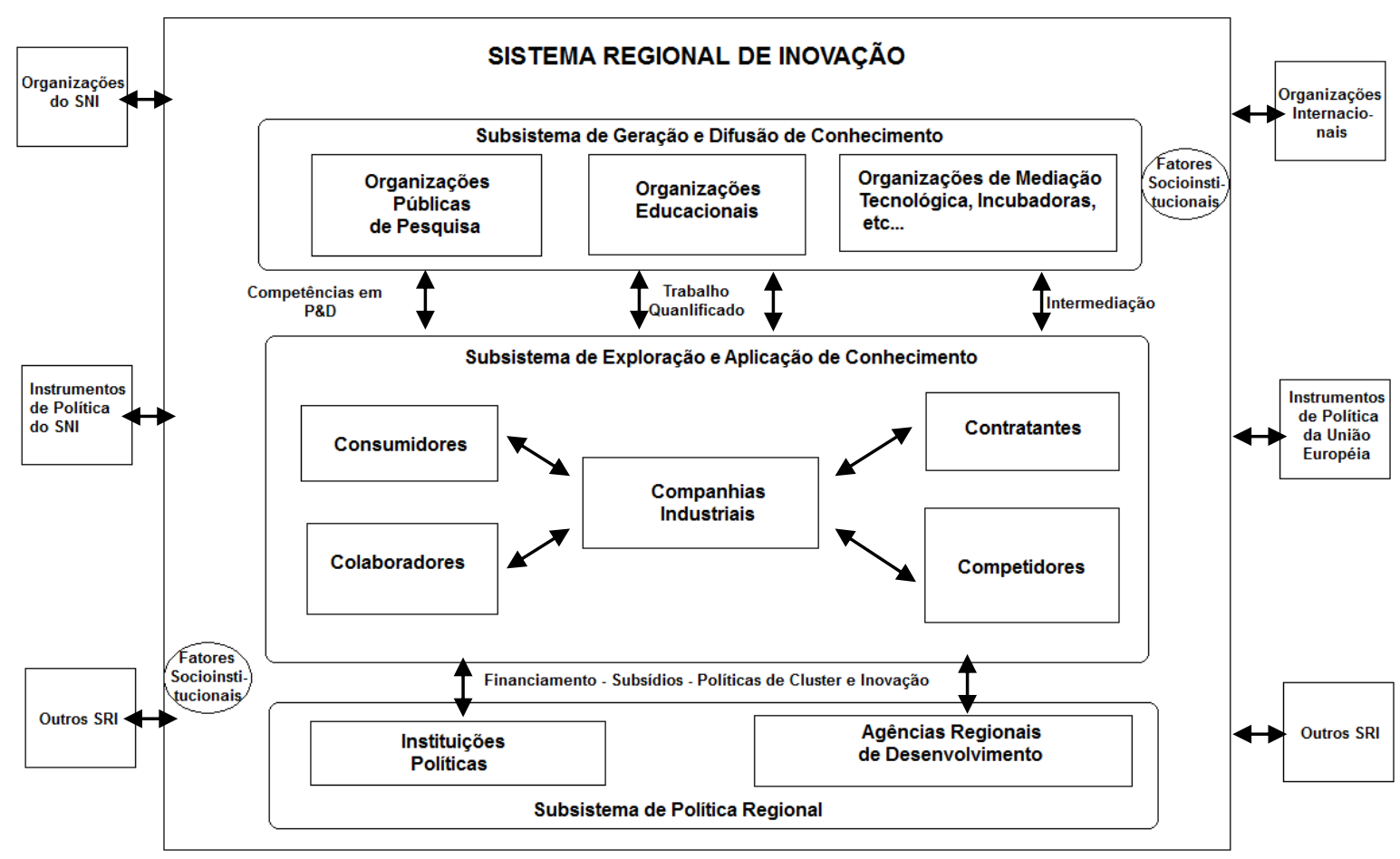

Fonte: Tödtling e Trippl (2005) e Arancegui (2009).

Arancegui (2009) esclarece que, em um SRI "dinâmico", é de se esperar que o subsistema de geração de conhecimento venha a interagir intensamente com $\mathrm{o}$ subsistema de uso de conhecimento e produção, de maneira a transmitir conhecimentos economicamente úteis, enquanto o segundo participaria manifestando suas necessidades tecnológicas e orientando os esforços realizados na esfera da geração de conhecimento. Além dessas duas formas básicas de interação, ainda haveria formas mais sofisticadas envolvendo fluxos de recursos humanos, recursos financeiros e a amplificação das competências proporcionadas pela própria transmissão do conhecimento. Agregado a esses dois subsistemas, teríamos um terceiro subsistema, formado por uma base de governança, que cumpriria a função de instância coordenadora, participando dos processos interativos de aprendizagem, seja induzindo-os através de instrumentos de fomento, seja de maneira mais ativa através de múltiplos tipos de incentivos.

No entanto, o conceito de sistema regional de inovação, fortemente ancorado no arcabouço institucional que o estrutura e no papel desempenhado pelas interações entre seus elementos-chave, é motivo de debates ainda correntes e, sobremaneira, 
inconclusos. Neste sentido, é importante ressaltar que o conceito continua sendo elaborado e aperfeiçoado. Críticas ao conceito ressaltam diferentes aspectos, como os problemas inerentes aos limites da região, uma menor ênfase na análise da configuração do setor produtivo comparativamente à questão das interações com instituições geradoras de conhecimentos, bem como as dificuldades para se estabelecer uma visão unificada e a inexistência de um paradigma ideal de funcionamento de um SRI. A partir destas e outras limitações, Markusen (1999) compreende o conceito como nebuloso e de difícil manipulação metodológica.

Cabe notar, ainda, que esse referencial teórico orienta a elaboração de análises essencialmente descritivas cuja intenção é entender como os processos de desenvolvimento e transferência de conhecimentos e tecnologias ocorrem dentro de um território particular. Simultaneamente, importantes implicações normativas tendem a ser extraídas desse tipo de análise. Sintetizando essa visão, Doloreux e Parto (2004) argumentam que as condições básicas para o estímulo à promoção de atividades inovativas incluem as características institucionais de uma região, sua infraestrutura de transferência de conhecimento e, também, a performance e a estratégia individual das firmas.

Não obstante algumas críticas à imprecisão do conceito, que ainda não encontraram uma solução categórica, é importante considerar que a abordagem territorial dos fenômenos inovativos baseada na noção de SRI é relativamente recente e apresenta diversos pontos fortes. O principal potencial desta abordagem está na sua capacidade de retratar as relações entre as diversas condições necessárias para que atividades inovativas prosperem em determinadas regiões, reforçando o seu desempenho em termos de inovação e competitividade. Mesmo que ainda não haja uma visão unificada do conceito, esse tipo de abordagem tem avançado significativamente nas últimas duas décadas, mostrando-se extremamente fecunda em termos de implicações normativas.

A utilização do conceito de sistema regional de inovação como base analítica para compreender-se a possibilidade de dinamização de atividades inovativas em determinado território pode ser referenciada à realidade fluminense. Como ponto de partida desta análise, é importante considerar que o atual quadro de um sistema científico e tecnológico regional do Rio de Janeiro mostra uma grande concentração de 
instituições geradoras de conhecimento e tecnologias ao lado de uma base produtiva pouco competitiva em diversos setores, apesar da importância econômica do estado e da presença de importantes grupos econômicos (cf. Britto et al., 2011:109).

Este estudo procura fornecer evidências preliminares a respeito de algumas características fundamentais do sistema regional de inovação do Estado do Rio de Janeiro. Com este intuito, optou-se por uma adaptação de um recorte analítico tradicional, baseado na diferenciação entre inputs e outputs de atividades inovativas como ponto de partida para a caracterização do SRI fluminense. É importante ressaltar que essa opção metodológica não implica seguir a lógica implícita no modelo linear de inovação, e sim o reconhecimento de que aquele recorte é instrumental para a compreensão das relações sistêmicas estabelecidas entre os atores envolvidos no processo inovativo.

Partindo dessa perspectiva, buscou-se analisar estatísticas secundárias relativas a três dimensões que conferem um maior ou menor dinamismo a um SRI particular: 1) os recursos financeiros mobilizados em escala regional para suportar o subsistema de geração de conhecimento; 2) as bases de competências dinamizadas a partir daquele suporte; 3) os impactos efetivos sobre o desempenho e a intensidade dos esforços inovativos no âmbito do setor empresarial. A partir desse tipo de procedimento, buscase tornar mais concreta a visão a respeito do objeto estudado (o SRI fluminense), inferindo-se conclusões sobre a conformação da sua estrutura e sobre a possibilidade de evolução ao longo de uma trajetória dinâmica de incremento do desempenho inovativo e de dinamização do desenvolvimento regional.

Nesse sentido, um maior detalhamento das análises desenvolvidas em cada bloco do estudo se faz necessário. O primeiro conjunto de informações, doravante Bloco 1, contempla uma investigação sobre o financiamento provido ao subsistema de geração de conhecimento no âmbito do SRI fluminense. Para tal, a análise recorre à noção instrumentalmente útil de inputs que se mostram necessários para a viabilização de atividades inovativas. Essa análise é ilustrada por informações relativas ao fomento à pesquisa e ao montante concedido de bolsas para estudantes e pesquisadores, provenientes de fundações de amparo à pesquisa (FAPs) e de outros organismos de financiamento. 
Com base na mesma lógica, o Bloco 2 reúne informações relativas à base de competências sobre a qual recaem os investimentos relacionados no Bloco 1. Organizando os dados dessa forma, pretende-se fazer um contraponto entre os insumos e os retornos das atividades inovativas no Estado do Rio de Janeiro, investigando se o subsistema de geração de conhecimento é capaz de gerar desdobramentos positivos sobre o fortalecimento de competência à indução de processos inovativos. A partir dessa análise, busca-se também identificar os pontos fortes e algumas especificidades da base de C\&T fluminense vis-à-vis demais regiões do país.

Através de um conjunto adicional de informações, que conformam o Bloco 3 do estudo, pretende-se destacar e dimensionar alguns aspectos relativos à performance inovativa do SRI fluminense, diretamente relacionados à utilização desse conhecimento pelo setor produtivo. Para tanto, procura-se discutir o comportamento da taxa de inovação levantada pela Pesquisa de Inovação Tecnológica (PINTEC), bem como informações sobre a intensidade dos esforços inovativos realizados pelo setor produtivo, que condicionam a sua capacidade de absorção de conhecimentos gerados em outras instâncias do SRI fluminense. Adicionalmente, serão também considerados dados de patentes discriminados para o Rio de Janeiro.

Com relação aos períodos de análise, deve-se fazer uma ressalva. A principal fonte de avaliação sobre o desempenho inovativo do setor empresarial, disponibilizada pela PINTEC/IBGE, compreende análises relativas aos períodos de 1998 a 2000, 2001 a 2003, 2003 a 2005 e 2006 a 2008. Desse modo, optou-se por priorizar a seleção de séries de dados abrangendo períodos que incluíssem desde a segunda metade da década de 1990 até o fim da década de 2000. Na análise desses dados, procurou-se, sempre que possível, confrontar informações relativas ao território fluminense com informações sobre outras unidades da federação.

\section{Primeiro Bloco: os inputs em C\&T no Estado do Rio de Janeiro}

\subsection{Critérios analíticos}

Nesta seção serão analisados dados relativos aos fluxos de investimento direcionados às atividades de C,T\&I no território fluminense. É importante, porém, que essas informações sejam interpretadas com o devido cuidado. Seria errôneo pensar que 
os volumes de recursos investidos em certos campos de conhecimento ou em determinadas instituições científico-tecnológicas (ICTs) são suficientes para precisar quais dentre esses são dominantes ou têm maior significância no SRI do Rio de Janeiro.

Outra peculiaridade que deve ser lembrada está nas especificidades de cada área de conhecimento. A área de Física experimental, por exemplo, demanda um volume de recursos relativamente alto para a instalação e manutenção de laboratórios e instrumentos essenciais para pesquisas. Logo, é necessário cuidado ao confrontar-se o volume de recursos destinados a duas áreas de conhecimento distintas, como Física e Economia, dado que a primeira exige um custo fixo elevado e a segunda tem grande parte dos recursos aplicados em seus projetos de pesquisa voltados à remuneração dos pesquisadores e à aquisição de software e hardware para o processamento de dados e estatísticas.

A forma mais adequada para entender os dados relativos a inputs de atividades inovativas, tais como serão apresentados nesta seção, parte da concepção de que esses dados denotam o grau de esforço de pesquisa incentivado e induzido a certas áreas potencialmente estratégicas pelas instituições que integram a governança do SRI. Logo, a análise dos dados do Bloco 1 visa fornecer uma compreensão mais nítida da origem da fonte de iniciativa predominante no SRI fluminense. Entendemos, portanto, que o financiamento de atividades de C\&T constitui um importante instrumento de política científico-tecnológica e que a identificação da sua fonte predominante ajuda a entender a configuração da governança de um determinado SRI (Cooke, 1992; Cooke et al., 1997; Braczyk et al., 1998).

Além da questão da iniciativa, vislumbra-se a possibilidade de identificar quais áreas de pesquisa demandam mais recursos relativamente a outras regiões do Brasil. Em particular, é possível identificar as áreas de conhecimento que recebem um aporte relativamente mais significativo de recursos, além de verificar as principais ICTs em cada unidade da federação.

\subsection{Dados e análise}

Como ponto de partida da análise, a Tabela 1 apresenta o padrão de distribuição dos recursos com bolsas distribuídas pelo CNPq entre as regiões brasileiras. A região Sudeste sempre se destacou pela sua participação nos investimentos em bolsas 
do país, com mais de $66 \%$ do total em 1996. Porém, ao longo dos 15 anos do período analisado, percebe-se uma tendência de redução da desigualdade de participação entre as regiões. A despeito do caráter ainda concentrado do investimento, é possível afirmar que o governo federal vem reforçando, gradativamente, um processo de desconcentração espacial do apoio à pesquisa científico-tecnológica no Brasil (Viotti et al., 2010).

\section{Tabela 1. Bolsas no país e no exterior: participação (\%) nos investimentos realizados segundo região - 1996-2011}

\begin{tabular}{lcccccc}
\hline & $\mathbf{1 9 9 6}$ & $\mathbf{1 9 9 9}$ & $\mathbf{2 0 0 2}$ & $\mathbf{2 0 0 5}$ & $\mathbf{2 0 0 8}$ & $\mathbf{2 0 1 1}$ \\
\hline Rio de Janeiro & 20,2 & 19,5 & 19,0 & 18,5 & 17,4 & 16,4 \\
Sudeste & 66,9 & 62,0 & 58,9 & 60,4 & 58,7 & 56,7 \\
Norte & 1,7 & 2,3 & 2,5 & 2,8 & 3,6 & 4,0 \\
Nordeste & 10,0 & 13,0 & 13,6 & 13,8 & 14,6 & 15,1 \\
Sul & 14,5 & 15,9 & 18,2 & 16,7 & 16,9 & 17,0 \\
C. Oeste & 6,8 & 6,7 & 6,8 & 6,3 & 6,1 & 7,2 \\
\hline
\end{tabular}

Fonte: CNPq.

Notas: Inclui recursos dos fundos setoriais; Não inclui bolsas de curta duração (fluxo contínuo); Não inclui os recursos repassados às FAPs, relativos ao Programa de Iniciação Científica Júnior, considerados no fomento à pesquisa.

(1) Bolsas no país: UF de destino; Bolsas no exterior: UF da instituição de vínculo (quando não há vínculo, os recursos sãocomputados em UF não informada).

(2) Os percentuais foram calculados desconsiderando os recursos da linha de UF Não informada.

(3) Pode incluir parcela de investimentos relativos a algumas institituições multiestaduais ou multirregionais, como Embrapa, porexemplo, cujos dados da unidade institucional não foram informados. (4) Inclui também recursos relativos aos programas de capacitação institucional doMCT (PCI) e do CNPq.

(5) Inclui, entre outros, investimentos referentes às ações de gestão, acompanhamento e avaliação.

Mesmo considerando a tendência à redução relativa dos investimentos federais realizados nos estados do Sudeste, observa-se que o volume recebido pelo Rio de Janeiro ainda é bastante significativo. Conforme podemos ver no Gráfico 1, em termos absolutos, os recursos alocados em bolsas para pesquisadores ligados a instituições fluminenses mantêm uma tendência de evolução muito próxima ao que o $\mathrm{CNPq}$ aloca para o conjunto dos estados da região Sudeste. Isso indica que, mesmo havendo uma redução gradual, em termos relativos, a presença do principal aparato federal de apoio à pesquisa - ao lado da CAPES - ainda é forte. 


\section{Gráfico 1. Investimento em bolsas no país e no exterior (milharesdereais)}

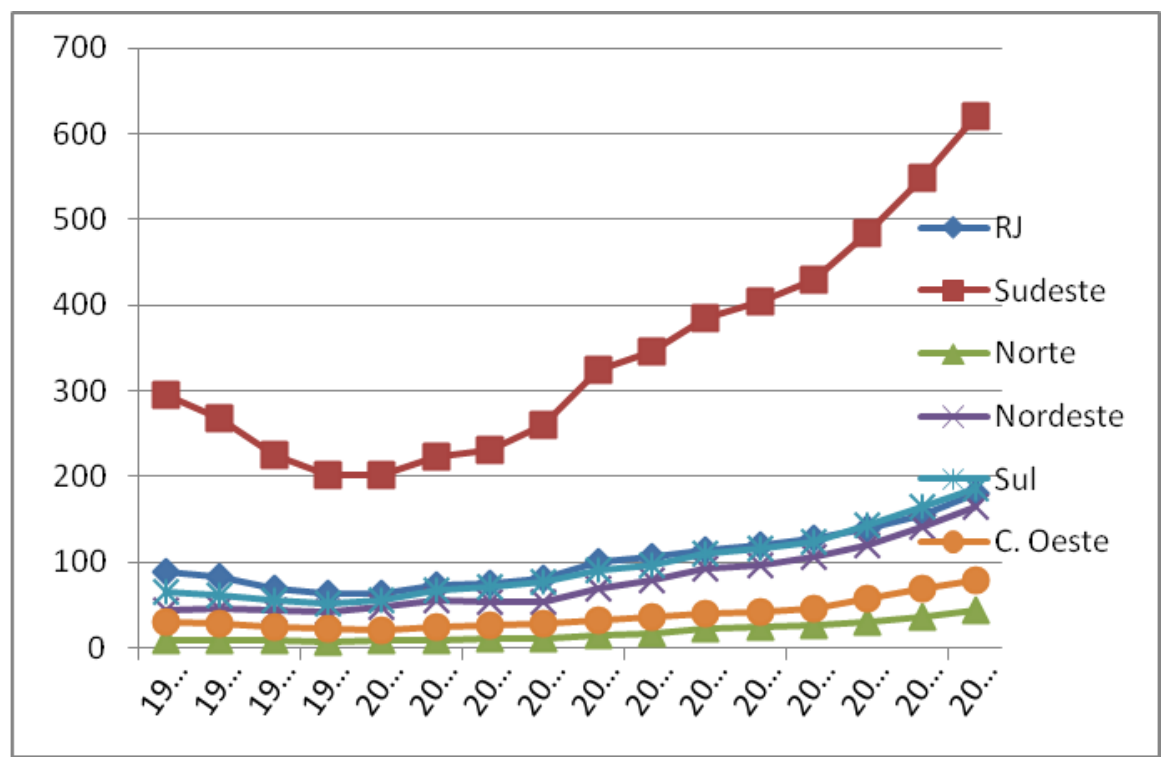

Fonte: CNPq.

Ainda com relação aos investimentos realizados pelo $\mathrm{CNPq}$, é possível considerar o montante de recursos direcionados para o apoio à pesquisa. Dentre as unidades da federação, o investimento em fomento no Rio de Janeiro só não supera o investimento em São Paulo. A terceira posição em investimentos no país vem sendo ocupada alternadamente pelo Distrito Federal e pelos estados de Minas Gerais e Rio Grande do Sul. Percebe-se a relevância dos estados do Sudeste no período 1996-2011 com papel de destaque ocupado pelo Rio.

Com relação aos recursos alocados em fomento e em bolsas da CAPES para alunos de pós-graduação, é possível considerar a participação do Estado do Rio de Janeiro no total nacional, conforme ilustrado pela Tabela 2. Podemos, novamente, notar a posição relevante do estado no cenário nacional dos investimentos em C\&T. O Rio é a segunda unidade da federação que mais recebe recursos da CAPES, inclusive superando outras regiões que contam com um número superior de universidades federais como Minas Gerais e Rio Grande do Sul. 
Tabela 2. Distribuição percentual $(\%)$ dos recursos alocados em bolsas e fomento no Brasil e no exterior pela CAPES por região e unidade da federação entre 2002 e 2011

\begin{tabular}{|c|c|c|c|c|c|c|c|c|c|c|}
\hline & 2002 & 2003 & 2004 & 2005 & 2006 & 2007 & 2008 & 2009 & 2010 & 2011 \\
\hline Norte & 3,3 & 2,4 & 2,5 & 3,2 & 3,7 & 3,5 & 4,0 & 3,8 & 3,8 & 3,6 \\
\hline $\mathrm{AM}$ & 0,6 & 0,7 & 0,7 & 0,8 & 1,1 & 0,9 & 1,0 & 1,2 & 1,1 & 1,0 \\
\hline PA & 2,1 & 1,4 & 1,4 & 1,7 & 1,8 & 1,8 & 1,9 & 1,7 & 1,7 & 1,8 \\
\hline TO & 0,1 & 0,1 & 0,1 & 0,1 & 0,2 & 0,2 & 0,4 & 0,4 & 0,3 & 0,3 \\
\hline RO & 0,1 & 0,1 & 0,1 & 0,1 & 0,2 & 0,1 & 0,2 & 0,2 & 0,2 & 0,2 \\
\hline $\mathrm{AC}$ & 0,1 & 0,1 & 0,1 & 0,1 & 0,2 & 0,2 & 0,2 & 0,2 & 0,2 & 0,2 \\
\hline RR & 0,1 & 0,1 & 0,1 & 0,3 & 0,2 & 0,2 & 0,2 & 0,1 & 0,2 & 0,1 \\
\hline AP & 0,0 & 0,0 & 0,0 & 0,1 & 0,1 & 0,0 & 0,1 & 0,1 & 0,1 & 0,1 \\
\hline Nordeste & 14,0 & 13,8 & 13,8 & 14,0 & 15,0 & 15,4 & 16,8 & 17,6 & 17,7 & 17,2 \\
\hline BA & 2,6 & 2,5 & 2,4 & 2,4 & 3,0 & 2,8 & 2,8 & 3,4 & 3,2 & 3,1 \\
\hline PE & 3,7 & 3,6 & 3,6 & 3,7 & 3,7 & 3,9 & 4,3 & 3,3 & 3,7 & 3,6 \\
\hline $\mathrm{CE}$ & 2,1 & 2,1 & 2,3 & 2,3 & 2,4 & 2,5 & 2,7 & 3,1 & 3,0 & 2,8 \\
\hline PB & 2,4 & 2,2 & 2,2 & 2,2 & 2,1 & 2,3 & 2,4 & 3,1 & 2,9 & 2,8 \\
\hline $\mathrm{AL}$ & 0,5 & 0,4 & 0,4 & 0,5 & 0,6 & 0,5 & 0,6 & 0,7 & 0,6 & 0,6 \\
\hline MA & 0,5 & 0,5 & 0,5 & 0,5 & 0,6 & 0,8 & 0,7 & 0,6 & 0,6 & 0,5 \\
\hline $\mathrm{SE}$ & 0,3 & 0,3 & 0,3 & 0,4 & 0,5 & 0,4 & 0,5 & 0,6 & 0,7 & 0,7 \\
\hline $\mathrm{RN}$ & 1,6 & 1,8 & 1,7 & 1,6 & 1,6 & 1,8 & 2,2 & 2,3 & 2,4 & 2,4 \\
\hline PI & 0,4 & 0,3 & 0,4 & 0,4 & 0,5 & 0,5 & 0,6 & 0,5 & 0,6 & 0,7 \\
\hline Sudeste & 42,7 & 45,4 & 45,2 & 44,5 & 44,5 & 44,3 & 41,7 & 42,3 & 40,3 & 39,8 \\
\hline ES & 0,9 & 0,8 & 0,7 & 0,7 & 0,8 & 0,8 & 0,9 & 1,1 & 1,1 & 1,1 \\
\hline MG & 10,1 & 9,8 & 10,4 & 9,7 & 9,8 & 9,6 & 10,4 & 9,7 & 9,9 & 10,4 \\
\hline RJ & 15,7 & 14,5 & 14,9 & 14,4 & 14,4 & 13,7 & 13,5 & 15,2 & 14,7 & 13,7 \\
\hline SP & 27,0 & 30,9 & 30,3 & 30,1 & 30,1 & 30,6 & 28,2 & 27,1 & 25,5 & 26,0 \\
\hline Sul & 20,8 & 19,4 & 19,3 & 20,4 & 18,8 & 18,9 & 18,5 & 18,0 & 20,4 & 20,8 \\
\hline $\mathrm{SC}$ & 4,4 & 4,4 & 4,4 & 4,2 & 3,7 & 3,5 & 3,8 & 3,5 & 4,0 & 4,3 \\
\hline $\mathrm{RS}$ & 10,7 & 9,6 & 9,6 & 10,4 & 9,6 & 9,6 & 9,3 & 9,4 & 9,9 & 9,9 \\
\hline PR & 5,6 & 5,4 & 5,3 & 5,8 & 5,4 & 5,8 & 5,4 & 5,1 & 6,4 & 6,6 \\
\hline Centro-Oeste & 5,7 & 5,6 & 5,6 & 5,4 & 5,9 & 6,3 & 6,8 & 7,1 & 6,3 & 6,5 \\
\hline DF & 3,4 & 3,5 & 3,4 & 3,3 & 3,4 & 3,4 & 3,7 & 3,5 & 2,7 & 3,0 \\
\hline GO & 1,1 & 1,0 & 1,0 & 1,0 & 1,1 & 1,3 & 1,3 & 1,6 & 1,8 & 1,6 \\
\hline MT & 0,6 & 0,6 & 0,7 & 0,7 & 0,9 & 0,9 & 0,9 & 1,0 & 0,8 & 0,8 \\
\hline MS & 0,6 & 0,5 & 0,5 & 0,5 & 0,6 & 0,6 & 0,8 & 0,9 & 1,0 & 1,1 \\
\hline Exterior & 2,5 & 2,8 & 2,4 & 2,0 & 1,5 & 1,3 & 0,9 & 0,4 & 0,5 & 0,5 \\
\hline Brasil & 100,0 & 100,0 & 100,0 & 100,0 & 100,0 & 100,0 & 100,0 & 100,0 & 100,0 & 100,0 \\
\hline
\end{tabular}

Fonte: Portal GeoCAPES.

As informações e estatísticas mencionadas reforçam a ideia de que o Rio de Janeiro é uma região que recebe relativamente mais recursos federais que a média do Brasil. De fato, seja pelo passado de quase dois séculos como capital federal, seja pela presença de um significativo número de ICTs e universidades federais, o Rio de Janeiro foi e continua sendo um espaço estratégico para as políticas científico-tecnológicas nacionais. Como principal exemplo desta característica, temos o caso do setor de 
petróleo e gás natural, cujos atores e organizações mais importantes voltados à geração de conhecimentos relevantes para o setor estão no Rio de Janeiro. ${ }^{4}$

$\mathrm{Na}$ mesma direção, podemos comparar a proporção alcançada pelos investimentos do $\mathrm{CNPq}$ no $\mathrm{PIB}$ das unidades da federação brasileiras, conforme apresentado na Tabela 3. O índice de investimento representa a razão entre as participações percentuais das inversões do CNPq realizadas dentro de um estado e o respectivo PIB estadual e as inversões do CNPq em todo o Brasil e o PIB nacional. Observa-se que o Rio de Janeiro apresenta um índice de investimento superior ao índice calculado para o Distrito Federal, evidenciando-se novamente o peso expressivo dos investimentos realizados neste estado com relação aos recursos totais destinados pelo CNPq.

\section{Tabela 3. Investimentos (1) do $\mathrm{CNPq}$ realizados em bolsas e no fomento à pesquisa em relação ao Produto Interno Bruto-PIB (2), segundo região e unidade da federação - 2002-2009}

\begin{tabular}{lcccccccc}
\hline & \multicolumn{7}{c}{ Índice do investimento / PIB (Brasil=100) } \\
& $\mathbf{2 0 0 2}$ & $\mathbf{2 0 0 3}$ & $\mathbf{2 0 0 4}$ & $\mathbf{2 0 0 5}$ & $\mathbf{2 0 0 6}$ & $\mathbf{2 0 0 7}$ & $\mathbf{2 0 0 8}$ & $\mathbf{2 0 0 9}$ \\
\hline Norte & 62 & 65 & 79 & 68 & 98 & 100 & 106 & 90 \\
Nordeste & 104 & 100 & 118 & 114 & 115 & 133 & 126 & 115 \\
Sudeste & 102 & 106 & 102 & 103 & 101 & 97 & 96 & 99 \\
$\quad$ MG & 115 & 108 & 105 & 104 & 106 & 104 & 99 & 111 \\
$\quad$ RJ & 165 & 174 & 157 & 160 & 150 & 157 & 144 & 145 \\
$\quad$ SP & 81 & 89 & 87 & 89 & 88 & 79 & 83 & 85 \\
Sul & 108 & 102 & 97 & 99 & 98 & 101 & 103 & 103 \\
$\quad$ RS & 142 & 135 & 137 & 138 & 135 & 137 & 146 & 143 \\
Centro-Oeste (3) & 86 & 75 & 78 & 81 & 75 & 71 & 80 & 84 \\
$\quad$ DF (3) & 162 & 136 & 136 & 136 & 121 & 112 & 134 & 144 \\
Brasil & 100 & 100 & 100 & 100 & 100 & 100 & 100 & 100 \\
\hline
\end{tabular}

Fonte: $\overline{\mathrm{CNPq}}$.

(1) Inclui recursos dos fundos setoriais; Não inclui os recursos do Programa de Interiorização do Trabalho em Saúde (convênio com o Ministério da Saúde vigente de 2001 a 2004).

(1) Bolsas no país: UF de destino; Bolsas no exterior: UF da inst. de vínculo (quando não há, os recursos são computados em UF não informada); Fomento: UF de destino (a partir de 2001, nos casos de eventos, a UF é da origem).

(2) Fonte: Instituto Brasileiro de Geografia e Estatística - IBGE (nova metodologia).

(3) Pode incluir parcela de investimentos do CNPq relativos a algumas instituições multiestaduais ou multirregionais, como Embrapa, por exemplo, cujos dados da unidade institucional não foram informados, o que pode superestimar os indicadores.

(4) Inclusive recursos referentes às ações de gestão, acompanhamento e avaliação e a concessões institucionais por meio de convênios.

\footnotetext{
${ }^{4}$ Como exemplos temos a PETROBRAS, a COPPE/UFRJ, o CENPES e grandes empresas multinacionais que têm investido em laboratórios de P\&D no Rio de Janeiro como FMC, Halliburton e Schlumberger.
} 
A partir da análise da posição relativa do Rio de Janeiro ante as demais regiões do Brasil em termos do fomento às atividades de C\&T, cabe identificar as ICTs e as áreas de conhecimento de maior peso no sistema científico-tecnológico fluminense. Com relação às instituições, podemos observar as dez instituições que mais recebem recursos (Tabela 4).

Conforme pode ser verificado, o peso das instituições federais é alto. Somente a UFRJ recebe cerca de $40 \%$ dos recursos alocados pelo CNPq em todo o Estado do Rio de Janeiro. Um dos fatores que colaboram em grande medida para a posição de liderança alcançada pela UFRJ é a presença de instituições integrantes do aparato de pesquisa do setor de petróleo e gás natural no parque tecnológico dessa universidade. Cabe ressaltar, no entanto, que esse parque tecnológico, mesmo constituindo um diferencial dessa universidade, provavelmente não é o único fator responsável por essa posição, que também é explicada pelo peso das competências científicas em diversas áreas das ciências básicas e em diversos campos da área de engenharia.

Tabela 4. Investimentos realizadospelo CNPq, no Rio de Janeiro, em bolsas e no fomento à pesquisa segundo instituição nos anos de 2006 a 2010

\begin{tabular}{lccccc}
\hline & $\mathbf{2 0 0 6}$ & $\mathbf{2 0 0 7}$ & $\mathbf{2 0 0 8}$ & $\mathbf{2 0 0 9}$ & $\mathbf{2 0 1 0}$ \\
\hline Universidade Federal do Rio de Janeiro & $44 \%$ & $41 \%$ & $42 \%$ & $42 \%$ & $39 \%$ \\
Fundação Oswaldo Cruz & $8 \%$ & $9 \%$ & $9 \%$ & $10 \%$ & $12 \%$ \\
Pontifícia Universidade Católica do Rio de Janeiro & $11 \%$ & $10 \%$ & $10 \%$ & $10 \%$ & $11 \%$ \\
Universidade do Estado do Rio de Janeiro & $6 \%$ & $5 \%$ & $6 \%$ & $6 \%$ & $7 \%$ \\
Universidade Federal Fluminense & $7 \%$ & $7 \%$ & $7 \%$ & $6 \%$ & $6 \%$ \\
Associação Instituto Nacional de Matemática Pura e & $3 \%$ & $3 \%$ & $4 \%$ & $2 \%$ & $4 \%$ \\
Aplicada & $2 \%$ & $2 \%$ & $2 \%$ & $2 \%$ & $2 \%$ \\
Universidade Federal Rural do Rio de Janeiro & $2 \%$ & $2 \%$ & $2 \%$ & $2 \%$ & $2 \%$ \\
Centro Brasileiro de Pesquisas Físicas & $2 \%$ & $2 \%$ & $2 \%$ & $2 \%$ & $1 \%$ \\
Instituto Nacional de Metrologia Normalização e & $1 \%$ & $1 \%$ & $1 \%$ & $2 \%$ & $1 \%$ \\
Qualidade Industrial-RJ & $15 \%$ & $19 \%$ & $15 \%$ & $15 \%$ & $15 \%$ \\
Laboratório Nacional de Computação Científica & & & &
\end{tabular}

Fonte: CNPq.

A participação da Fundação Oswaldo Cruz (FIOCRUZ), outra instituição federal, recebendo entre $8 \%$ e $12 \%$ do total dos recursos destinados pelo CNPq ao Rio de Janeiro, evidencia o peso que o setor de saúde tem no aparato de pesquisa localizado no Estado do Rio. Das demais instituições, temos como notável a presença das cinco 
principais universidades fluminenses (PUC-RJ, UERJ, UFF e UFRRJ, além da já mencionada UFRJ), dentre as quais somente duas não são federais. Fora as universidades mencionadas, temos outras cinco ICTs, todas federais. Ou seja, em um balanço geral das dez instituições que mais recebem recursos para pesquisa e bolsas do CNPq, somente duas não são federais, uma universidade estadual, a UERJ, e uma instituição particular, a PUC-RJ.

Em função desse quadro, percebe-se que o sistema regional de inovação do Rio de Janeiro tem influência da esfera de poder central, destacando-se a marcante presença do governo federal em sua estruturação e em sua estrutura de governança.

Para avaliar melhor essa tendência, é possível considerar também informações relativas à atuação da esfera regional no financiamento ao esforço de geração de conhecimento no Rio de Janeiro. O principal órgão responsável por tal dimensão é a Fundação de Amparo à Pesquisa do Estado do Rio de Janiero (FAPERJ). No Gráfico 2, que segue, podemos ter uma visão comparativa entre a participação das três grandes instituições voltadas ao financiamento de atividades científicas e tecnológicas tratadas.

\section{Gráfico 2. Peso $(\%)$ dos valores investidos em bolsas e fomento à pesquisa por}

CAPES, CNPq e FAPERJ no PIB Fluminense - 2002 a 2009

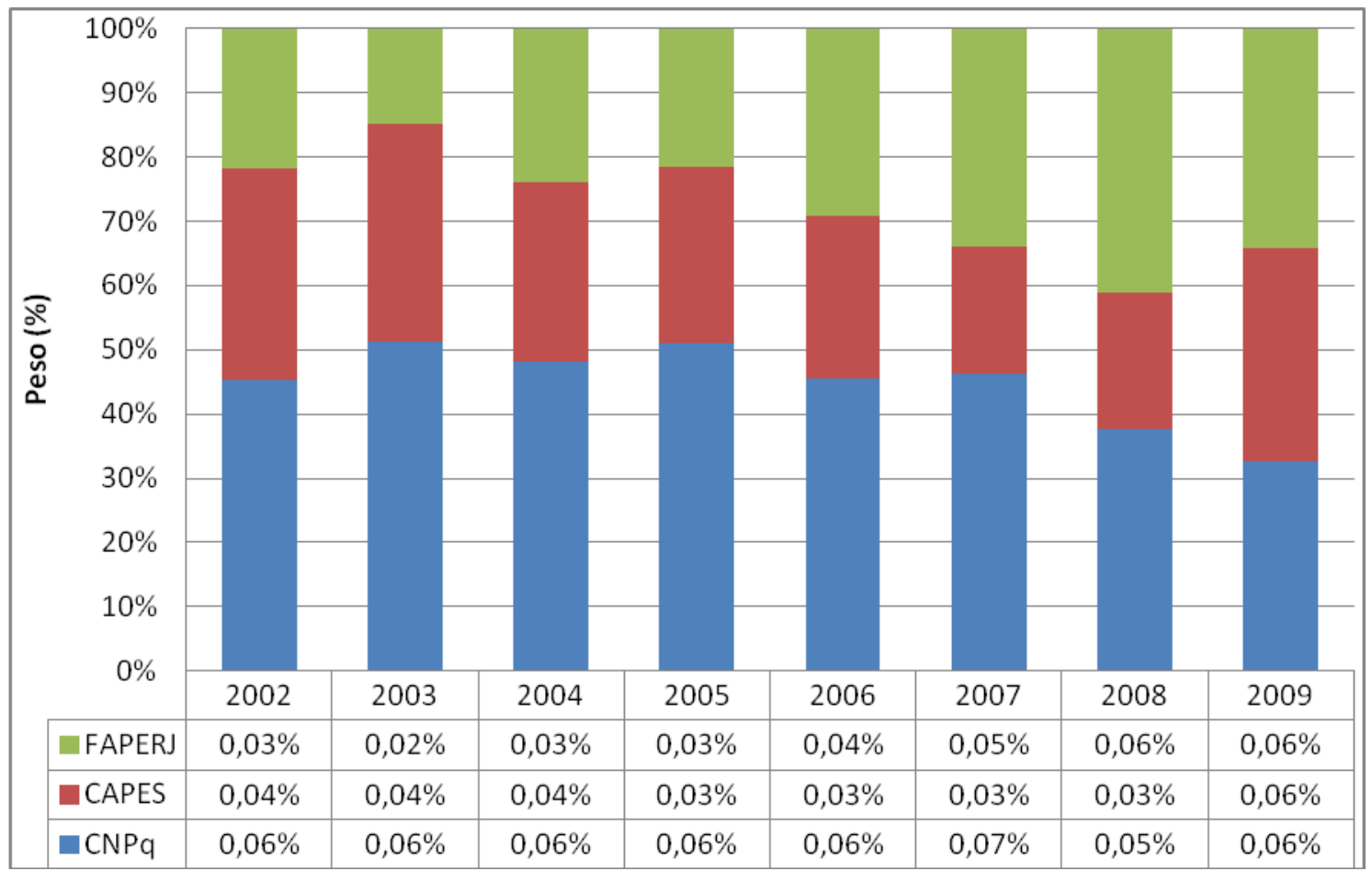

Fonte: CNPq, Portal GeoCAPES e Anuário Estatístico CEPERJ 2012. 
Primeiramente, deve-se notar certa predominância da esfera central no financiamento ao sistema científico-tecnológico do Rio de Janeiro em comparação com a esfera regional. Somando a participação de CAPES e CNPq no PIB Fluminense, podemos concluir que os investimentos federais em bolsas e amparo à pesquisa giram em torno de $0,1 \%$ enquanto que o valor máximo atingido pela participação da FAPERJ é de $0,06 \%$. Além disso, a participação da FAPERJ no financiamento de atividades de pesquisa se torna menos relevante em termos relativos à medida que se reconhece que há outras fontes de recursos importantesque não estão diretamente ligadas ao meio acadêmico, como a Financiadora de Estudos e Projetos (FINEP), o Banco Nacional de Desenvolvimento Economico e Social (BNDES) e as empresas do setor privado ${ }^{5}$.

Outro ponto digno de nota é a evolução significativa dos recursos aportados pela FAPERJ na década passada. Especialmente após o biênio 2006-2007, é possível verificar um aumento substancial da participação do volume de recursos alocados pela instituição no PIB estadual. Esse avanço se insere em um processo mais geral de reestruturação da máquina pública que vem se desenvolvendo desde meados da década de 2000. Essa atuação é estratégica por permitir um enfoque mais específico às políticas de C\&T regionais, dado que o governo estadual teria um grau de comprometimento maior com o desempenho econômico regional e suas potencialidades econômicas. No entanto, é importante ressaltar que ainda são necessários avanços, tanto no processo de reestruturação mencionado como na participação efetiva da FAPERJ e de outras instituições regionais na condução dos esforços de geração e transmissão de conhecimento e tecnologias das ICTs para a estrutura produtiva fluminense.

Como forma de estabelecer um parâmetro de comparação, podemos confrontar dados a respeito das três fundações de amparo à pesquisa dos três principais estados do Sudeste. No ano de 2010, enquanto a FAPERJ alocou cerca de R $\$ 265.403 .000,00^{6} \mathrm{em}$ bolsas e auxílio à pesquisa, a Fundação de Amparo à Pesquisa do Estado de Minas Gerais (FAPEMIG) investiu R\$ 239.117.335,47 e a Fundação de Amparo à Pesquisa do Estado de São Paulo (FAPESP) direcionou a quantia de R $\$ 780.033 .468,44^{8}$ aos mesmos destinos. Neste sentido é possível perceber que, mesmo com os avanços

\footnotetext{
${ }^{5}$ Não foi possível obter dados para o esforço de financiamento privado de C,T\&I. A PINTEC/IBGE perde significância estatística quando são feitos excessivos recortes ao nível estadual.

${ }^{6}$ Estimativa do Anuário Estatístico CEPERJ 2012.

${ }^{7}$ De acordo com o Relatório de Atividades FAPEMIG 2010.

${ }^{8}$ In: http://www.fapesp.br/estatisticas/pagamentos/2010 - Acesso em 13/05/2013.
} 
recentes relativos à atuação da FAPERJ no papel de amparo à pesquisa - inclusive investindo um volume de recursos superior à FAPEMIG -, ainda há um gap significativo quando comparada à FAPESP.

3. Segundo Bloco: base de conhecimento e esforços inovativos no âmbito do SRI fluminense

Obviamente, todo o aparato de financiamento em atividades ligadas à ciência, tecnologia e inovação deve respaldar sua ação em uma base de competências capaz de receber esses recursos e processá-los de forma a gerar conhecimento. É conveniente, também, que esse conhecimento seja passível de assimilação pela estrutura produtiva da economia. No caso do Rio de Janeiro, assim como foi verificado na seção anterior deste texto, é possível identificar uma posição de destaque quanto à presença de doutores, titulados e também empregados, participando do processo econômico dessa região.

Uma importante fonte de informações relativa a este aspecto pode ser encontrada no estudo realizado por Viotti et al. (2010), no qual é analisada, de maneira mais ampla e profunda, a base de conhecimento em todo o Brasil. Uma primeira característica apontada pelos autores é a significativa concentração do número de doutores nos estados da região Sudeste, com o total de doutores titulados no Rio de Janeiro entre 1996 e 2008 representando 15,6\% do total nacional, desempenho somente superado pelos expressivos 54,8\% apresentados por São Paulo.

Tabela 5. Número de doutores titulados no período 1996-2008 nas cinco grandes regiões brasileiras e nas cinco unidades da federação que mais titularam doutores no período

\begin{tabular}{rcc}
\hline & Número de Doutores & Peso (\%) \\
\hline Sudeste & 67.626 & 77,7 \\
\multicolumn{1}{c}{ SP } & 47.691 & 54,8 \\
RJ & 13.548 & 15,6 \\
MG & 6.241 & 7,2 \\
Sul & 10.899 & 12,5 \\
\multicolumn{1}{c}{ RS } & 6.460 & 7,4 \\
$\quad$ PR & 2.265 & 2,6 \\
Nordeste & 5.761 & 6,6 \\
Centro-Oeste & 2.138 & 2,5 \\
Norte & 639 & 0,7 \\
Brasil & 87.063 & 100,0 \\
\hline
\end{tabular}


Fonte: Elaboração a partir de Viotti et al.(2010).

A posição expressiva do Rio de Janeiro na alocação de recursos para C\&T está em consonância com a dimensão da sua base de competências no cenário nacional. No entanto, é importante notar que ocorreu uma desconcentração espacial quanto ao aspecto mencionado, favorecendo as regiões Norte, Nordeste, Sul e Centro-oeste.

Entre 1996 e 2008, observa-se que o número de doutores titulados em todo o país cresceu $278,3 \%$, contra $198,3 \%$ no Sudeste, provocado, principalmente pelo desempenho de São Paulo, com um crescimento de 154,4\%. O Rio de Janeiro também foi afetado pela desconcentração, crescendo um pouco menos do que a média nacional, com crescimento de $272,9 \%$ no período considerado (ver Tabela 6).

\section{Tabela 6.Taxa de crescimento percentual do número de doutores titulados no}

Brasil por região e unidade da federação, 1996-2008

\begin{tabular}{lc}
\hline \multicolumn{1}{c}{$\begin{array}{c}\text { Região / Unidade } \\
\text { da federação }\end{array}$} & $\begin{array}{c}\mathbf{1 9 9 6} \\
\mathbf{a ~ 2 0 0 8}\end{array}$ \\
\hline Região Sudeste & 198,3 \\
MG & 505,2 \\
ES & 560,0 \\
RJ & 272,9 \\
SP & 154,4 \\
Região Sul & 682,5 \\
Região Nordeste & $2.487,5$ \\
Região Centro-Oeste & 840,5 \\
Região Norte & 438,1 \\
Brasil & 278,3 \\
\hline Fonte: Elaboração a partir deViotti el al(2010).
\end{tabular}

Nesse contexto de estímulos à desconcentração espacial da população de doutores, torna-se necessário compensar essa redução relativa através da participação dos atores regionais como as universidades estaduais, a FAPERJ e a Secretaria de Ciência e Tecnologia. Em especial, uma maior atuação de instituições estaduais na configuração do sistema científico-tecnológico fluminense pode ser importante. À medida que o poder público estadual consiga articular e por em curso políticas para a transferência de tecnologia desde o citado sistema, a performance do sistema regional de inovação do Rio de Janeiro tende a ser reforçada. Cabe notar, inclusive, que não basta participar através do financiamento e da indução dos esforços de pesquisa, mas é 
essencial atuar nas interações entre o setor produtivo e as instituições geradoras de conhecimento.

Os dados relativos às quantidades de programas de pós-graduação com doutorado por unidades da federação também ajudam a ilustrar o processo de desconcentração espacial da base de competências brasileira. Conforme aponta a Tabela 7, apesar do número total de programas ter subido de 127, em 1998, para 191, em 2008, o peso percentual dos programas de doutorado fluminenses no total do país diminuiu em cerca de dois pontos percentuais. Note-se que essa redução de participação percentual, mesmo que tenha sido gradual, pode ser verificada com mais ênfase a partir de 2003, quando os programas de doutorado no Rio representavam 15,8\% e passaram a representar $14,5 \%$ do total nacional no fim do período analisado. No período anterior, para efeitos de comparação, a participação fluminense nessa estatística oscilou entre $16,0 \%$ e $16,3 \%$.

Comparando o número de doutores titulados com o número de doutores efetivamente empregados (ver Tabela 8), é possível ver que tanto o Rio de Janeiro como São Paulo absorveram um número menor de doutores do que geraram entre 1996 e 2008, refletindo o papel desses estados na formação de competências científicas que, em parte, tendem a migrar para outros estados. Neste sentido, constata-se que a base de criação de competências científicas presente no Rio é a segunda mais significativa do Brasil. 
Tabela 7. Número e percentagem de programas de doutorado por unidade da federação, Brasil, 1998-2008

\begin{tabular}{|c|c|c|c|c|c|c|c|c|c|c|c|c|c|c|c|c|c|c|c|c|c|c|}
\hline \multirow{2}{*}{ UF } & \multicolumn{2}{|c|}{1998} & \multicolumn{2}{|c|}{1999} & \multicolumn{2}{|c|}{2000} & \multicolumn{2}{|c|}{2001} & \multicolumn{2}{|c|}{2002} & \multicolumn{2}{|c|}{2003} & \multicolumn{2}{|c|}{2004} & \multicolumn{2}{|c|}{2005} & \multicolumn{2}{|c|}{2006} & \multicolumn{2}{|c|}{2007} & \multicolumn{2}{|c|}{2008} \\
\hline & $\mathrm{N}^{\mathrm{o}}$ & $\%$ & $\mathrm{~N}^{\mathrm{o}}$ & $\%$ & $\mathrm{~N}^{\mathrm{o}}$ & $\%$ & $\mathrm{~N}^{\mathrm{o}}$ & $\%$ & $\mathrm{~N}^{\mathrm{o}}$ & $\%$ & $\mathrm{~N}^{\mathrm{o}}$ & $\%$ & $\mathrm{~N}^{\mathrm{o}}$ & $\%$ & $\mathrm{~N}^{\mathrm{o}}$ & $\%$ & $\mathrm{~N}^{\mathrm{o}}$ & $\%$ & $\mathrm{~N}^{\mathrm{o}}$ & $\%$ & $\mathrm{~N}^{\mathrm{o}}$ & $\%$ \\
\hline Brasil & 782 & 100,0 & 789 & 100,0 & 802 & 100,0 & 912 & 100,0 & 923 & 100,0 & 942 & 100,0 & 1.058 & 100,0 & 1.097 & 100,0 & 1.185 & 100,0 & 1.245 & 100,0 & 1.320 & 100,0 \\
\hline SP & 372 & 47,6 & 372 & 47,1 & 375 & 46,8 & 396 & 43,4 & 398 & 43,1 & 403 & 42,8 & 425 & 40,2 & 440 & 40,1 & 449 & 37,9 & 457 & 36,7 & 472 & 35,8 \\
\hline RJ & 127 & 16,2 & 129 & 16,3 & 131 & 16,3 & 147 & 16,1 & 148 & 16,0 & 149 & 15,8 & 164 & 15,5 & 171 & 15,6 & 183 & 15,4 & 184 & 14,8 & 191 & 14,5 \\
\hline RS & 73 & 9,3 & 74 & 9,4 & 77 & 9,6 & 83 & 9,1 & 85 & 9,2 & 87 & 9,2 & 111 & 10,5 & 112 & 10,2 & 121 & 10,2 & 126 & 10,1 & 132 & 10,0 \\
\hline MG & 62 & 7,9 & 63 & 8,0 & 64 & 8,0 & 86 & 9,4 & 88 & 9,5 & 92 & 9,8 & 97 & 9,2 & 100 & 9,1 & 116 & 9,8 & 121 & 9,7 & 127 & 9,6 \\
\hline PR & 24 & 3,1 & 25 & 3,2 & 26 & 3,2 & 38 & 4,2 & 38 & 4,1 & 39 & 4,1 & 45 & 4,3 & 45 & 4,1 & 54 & 4,6 & 59 & 4,7 & 67 & 5,1 \\
\hline PE & 29 & 3,7 & 28 & 3,5 & 29 & 3,6 & 34 & 3,7 & 34 & 3,7 & 36 & 3,8 & 43 & 4,1 & 45 & 4,1 & 48 & 4,1 & 50 & 4,0 & 55 & 4,2 \\
\hline DF & 19 & 2,4 & 20 & 2,5 & 20 & 2,5 & 26 & 2,9 & 26 & 2,8 & 27 & 2,9 & 36 & 3,4 & 36 & 3,3 & 43 & 3,6 & 45 & 3,6 & 51 & 3,9 \\
\hline SC & 19 & 2,4 & 19 & 2,4 & 19 & 2,4 & 20 & 2,2 & 21 & 2,3 & 22 & 2,3 & 30 & 2,8 & 33 & 3,0 & 34 & 2,9 & 37 & 3,0 & 43 & 3,3 \\
\hline BA & 14 & 1,8 & 14 & 1,8 & 15 & 1,9 & 16 & 1,8 & 16 & 1,7 & 16 & 1,7 & 18 & 1,7 & 23 & 2,1 & 30 & 2,5 & 36 & 2,9 & 39 & 3,0 \\
\hline CE & 10 & 1,3 & 10 & 1,3 & 10 & 1,2 & 13 & 1,4 & 13 & 1,4 & 13 & 1,4 & 16 & 1,5 & 18 & 1,6 & 19 & 1,6 & 23 & 1,8 & 28 & 2,1 \\
\hline PB & 8 & 1,0 & 9 & 1,1 & 10 & 1,2 & 14 & 1,5 & 15 & 1,6 & 16 & 1,7 & 18 & 1,7 & 18 & 1,6 & 20 & 1,7 & 23 & 1,8 & 23 & 1,7 \\
\hline PA & 7 & 0,9 & 7 & 0,9 & 7 & 0,9 & 10 & 1,1 & 10 & 1,1 & 10 & 1,1 & 13 & 1,2 & 13 & 1,2 & 14 & 1,2 & 17 & 1,4 & 18 & 1,4 \\
\hline $\mathbf{R N}$ & 7 & 0,9 & 8 & 1,0 & 8 & 1,0 & 10 & 1,1 & 10 & 1,1 & 10 & 1,1 & 13 & 1,2 & 12 & 1,1 & 16 & 1,4 & 17 & 1,4 & 18 & 1,4 \\
\hline GO & 1 & 0,1 & 1 & 0,1 & 1 & 0,1 & 5 & 0,5 & 6 & 0,7 & 6 & 0,6 & 8 & 0,8 & 8 & 0,7 & 10 & 0,8 & 15 & 1,2 & 16 & 1,2 \\
\hline $\mathbf{A M}$ & 4 & 0,5 & 4 & 0,5 & 4 & 0,5 & 4 & 0,4 & 5 & 0,5 & 6 & 0,6 & 8 & 0,8 & 8 & 0,7 & 9 & 0,8 & 13 & 1,0 & 15 & 1,1 \\
\hline ES & 3 & 0,4 & 3 & 0,4 & 3 & 0,4 & 5 & 0,5 & 5 & 0,5 & 5 & 0,5 & 5 & 0,5 & 5 & 0,5 & 5 & 0,4 & 7 & 0,6 & 7 & 0,5 \\
\hline MS & - & - & - & - & - & - & 1 & 0,1 & 1 & 0,1 & 1 & 0,1 & 3 & 0,3 & 3 & 0,3 & 4 & 0,3 & 5 & 0,4 & 5 & 0,4 \\
\hline SE & - & - & - & - & - & - & 1 & 0,1 & 1 & 0,1 & 1 & 0,1 & 1 & 0,1 & 1 & 0,1 & 2 & 0,2 & 2 & 0,2 & 4 & 0,3 \\
\hline $\mathbf{A L}$ & 3 & 0,4 & 3 & 0,4 & 3 & 0,4 & 2 & 0,2 & 2 & 0,2 & 2 & 0,2 & 3 & 0,3 & 3 & 0,3 & 3 & 0,3 & 3 & 0,2 & 3 & 0,2 \\
\hline MT & - & - & - & - & - & - & - & - & - & - & - & - & - & - & 1 & 0,1 & 1 & 0,1 & 1 & 0,1 & 2 & 0,2 \\
\hline RO & - & - & - & - & - & - & - & - & - & - & - & - & - & - & 1 & 0,1 & 1 & 0,1 & 1 & 0,1 & 1 & 0,1 \\
\hline AP & - & - & - & - & - & - & - & - & - & - & - & - & - & - & - & - & 1 & 0,1 & 1 & 0,1 & 1 & 0,1 \\
\hline MA & - & - & - & - & - & - & 1 & 0,1 & 1 & 0,1 & 1 & 0,1 & 1 & 0,1 & 1 & 0,1 & 1 & 0,1 & 1 & 0,1 & 1 & 0,1 \\
\hline PI & - & - & - & - & - & - & - & - & - & - & - & - & - & - & - & - & 1 & 0,1 & 1 & 0,1 & 1 & 0,1 \\
\hline $\mathbf{A C}$ & - & - & - & - & - & - & - & - & - & - & - & - & - & - & - & - & - & - & - & - & - & - \\
\hline RR & - & - & - & - & - & - & - & - & - & - & - & - & - & - & - & - & - & - & - & - & - & - \\
\hline TO & - & - & - & - & - & - & - & - & - & - & - & - & - & - & - & - & - & - & - & - & - & - \\
\hline
\end{tabular}


Tabela 8. Doutores titulados no Brasil no período 1996-2008, empregados em 2008, por unidades da federação da titulação e do emprego

\begin{tabular}{|c|c|c|c|c|c|c|}
\hline \multirow{2}{*}{ UF } & \multicolumn{2}{|c|}{ Titulados na UF } & \multicolumn{2}{|c|}{ Empregados na UF } & \multicolumn{2}{|c|}{ Saldo } \\
\hline & (A) & (A\%) & (B) & (B\%) & $(B-A)$ & $(\mathrm{A} \%-\mathrm{B} \%)$ \\
\hline Brasil & 62.077 & 100,0 & 62.077 & 100,0 & - & - \\
\hline SP & 33.315 & 53,7 & 19.541 & 31,5 & -13.774 & 22,2 \\
\hline RJ & 9.532 & 15,4 & 8.253 & 13,3 & -1.279 & 2,1 \\
\hline RS & 4.804 & 7,7 & 5.103 & 8,2 & 299 & $-0,5$ \\
\hline MG & 4.590 & 7,4 & 5.980 & 9,6 & 1.390 & $-2,2$ \\
\hline PR & 1.727 & 2,8 & 4.496 & 7,2 & 2.769 & $-4,5$ \\
\hline SC & 1.611 & 2,6 & 2.032 & 3,3 & 421 & $-0,7$ \\
\hline PE & 1.428 & 2,3 & 1.515 & 2,4 & 87 & $-0,1$ \\
\hline DF & 1.388 & 2,2 & 2.440 & 3,9 & 1.052 & $-1,7$ \\
\hline BA & 878 & 1,4 & 2.364 & 3,8 & 1.486 & $-2,4$ \\
\hline $\mathbf{C E}$ & 775 & 1,2 & 1.365 & 2,2 & 590 & $-1,0$ \\
\hline PB & 660 & 1,1 & 1.218 & 2,0 & 558 & $-0,9$ \\
\hline $\mathbf{R N}$ & 460 & 0,7 & 640 & 1,0 & 180 & $-0,3$ \\
\hline PA & 318 & 0,5 & 1.012 & 1,6 & 694 & $-1,1$ \\
\hline GO & 197 & 0,3 & 1.145 & 1,8 & 948 & $-1,5$ \\
\hline AM & 162 & 0,3 & 572 & 0,9 & 410 & $-0,7$ \\
\hline ES & 116 & 0,2 & 840 & 1,4 & 724 & $-1,2$ \\
\hline $\mathbf{A L}$ & 75 & 0,1 & 501 & 0,8 & 426 & $-0,7$ \\
\hline MS & 15 & 0,0 & 847 & 1,4 & 832 & $-1,3$ \\
\hline MA & 13 & 0,0 & 220 & 0,4 & 207 & $-0,3$ \\
\hline $\mathbf{S E}$ & 12 & 0,0 & - & - & -12 & 0,0 \\
\hline RN & 1 & 0,0 & 183 & 0,3 & 182 & $-0,3$ \\
\hline AC & - & - & 153 & 0,2 & 153 & $-0,2$ \\
\hline $\mathbf{A P}$ & - & - & 76 & 0,1 & 76 & $-0,1$ \\
\hline MT & - & - & 811 & 1,3 & 811 & $-1,3$ \\
\hline PI & - & - & 406 & 0,7 & 406 & $-0,7$ \\
\hline RR & - & - & 131 & 0,2 & 131 & $-0,2$ \\
\hline TO & - & - & 233 & 0,4 & 233 & $-0,4$ \\
\hline
\end{tabular}

Fonte: Viotti el al(2010).

Notas: Dos doutores titulados no período 1996-2008, 62.492 encontravam-se empregados de acordo com a RAIS de 2008. Contudo, apenas 62.077 tiveram a unidade da federação dos estabelecimentos que os empregavam identificada, isto é, não foi possível identificar a unidade da federação de 415 doutores.

Após esse breve dimensionamento e contextualização da base de competências gerada no Estado do Rio de Janeiro, cabe analisar suas especializações. Com este intuito, podemos avaliar a distribuição percentual dos doutores titulados no Rio, no Brasil e em outras unidades da federação entre 1996 e 2008 segundo as grandes áreas de conhecimento. A partir das informações apresentadas no Gráfico 3, percebe-se a relevância de disciplinas ligadas às engenharias na formação da base de competências fluminense. Nesta área, é nítida a disparidade entre o Rio e as demais regiões brasileiras 
selecionadas, enquanto o quantitativo de doutores titulados nas instituições fluminenses representou 19,0\%, a média nacional foi inferior aos 13,0\% no período de 1996 a 2008. Uma hipótese para essa característica - a liderança do Rio na proporção de doutores na área de engenharias - é a presença de um significativo e crescente aparato de pesquisa ligado à indústria petrolífera.

Gráfico 3. Distribuição (\%) do número de doutores titulados no Brasil, São Paulo, Rio de Janeiro, Minas Gerais e Rio Grande do Sul por unidade da federação e grande área do conhecimento, 1996-2008

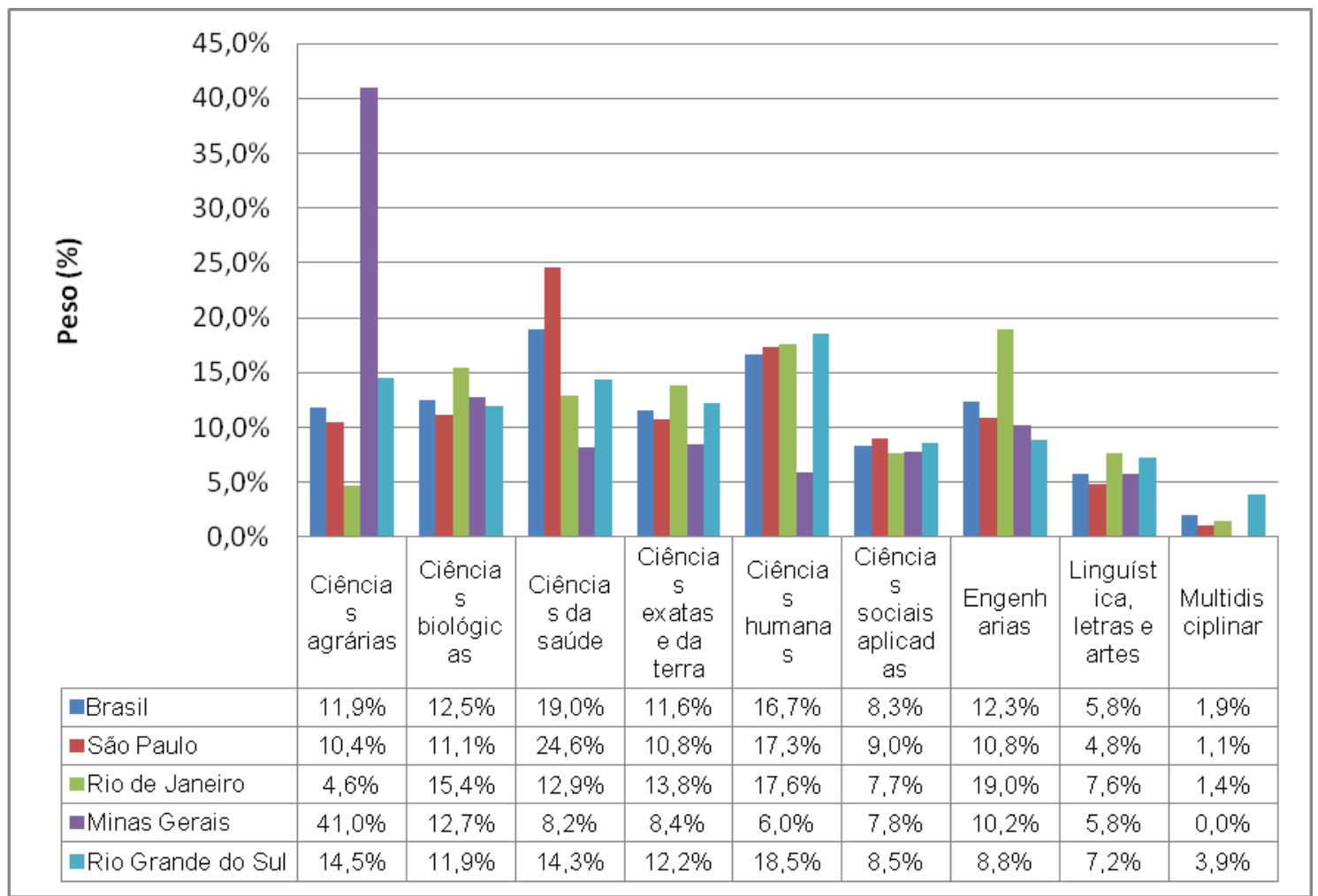

Fonte: Elaboração a partir de Viotti el al(2010).

Outros dois pontos dignos de nota são o desempenho fluminense na titulação de doutores em ciências exatas e da terra e em ciências biológicas.

Nas ciências biológicas, esse desempenho, possivelmente, está fortemente ligado ao Polo de Biotecnologia do Rio de Janeiro (BIORIO). O caso das ciências exatas e da terra pode, em parte, ser relacionado ao setor de petróleo e gás. Obviamente que os recursos humanos formados nesta área e na área de engenharias não são integralmente direcionados ao setor de petróleo e gás. No entanto, é interessante 
perceber a relação de atividades das indústrias petrolífera e parapetrolífera com especializações presentes nessa área de conhecimento como, por exemplo, as geociências, a física e a química. A presença de instituições como o Centro Brasileiro de Pesquisas Físicas (CBPF) e o Instituto Nacional de Matemática Pura e Aplicada (IMPA) no estado também colaboram para o considerável peso desta área de conhecimento na base de competências fluminense.

No entanto, para que essas competências acumuladas no campo científico possam efetivamente se converter em fontes de capacitação inovativa, é necessário que haja certa correspondência em termos do incremento das capacitações empresariais. Nesse sentido, uma análise mais detalhadas das informações gerais regionalizadas da PINTEC referentes à intensidade dos esforços inovativos também revela algumas características adicionais importantes do SRI fluminense em termos das capacitações empresariais. Em particular, é possível supor que a exploração do potencial da base de conhecimento que emerge da infraestrutura de C\&T relativamente sofisticada característica do SRI fluminense requer, em simultâneo, uma intensificação de esforços inovativos realizados pelo setor produtivo.

No que se refere especificamente aos esforços de pesquisa e desenvolvimento (P\&D), a Tabela 9 indica que o Rio de Janeiro localiza-se entre a $2^{\mathrm{a}}$ e $3^{\mathrm{a}}$ posições entre os estados com maior "intensidade" dos esforços em P\&D medidos pela relação entre o montante total desses gastos e a receita total das empresas investigadas pela PINTEC. Observa-se também uma evolução positiva da posição do estado ao longo das diversas pesquisas no que se refere ao indicador dado pela relação entre pessoal envolvido com atividades de P\&D e o quadro geral de pessoal. Provavelmente, esse desempenho reflete a presença de grandes empresas com sede no estado (como a Petrobras) que realizam dispêndios absolutos elevados em atividades de P\&D. No tocante ao indicador dado pelo percentual de empresas com gastos em P\&D em relação ao total de empresas investigadas pela PINTEC, a posição do estado melhorou sensivelmente na última rodada da pesquisa, referente ao período 2006-2008. 
Tabela 9.Indicadores de Gastos e Pessoal em P\&Ddas indústrias extrativas e de transformação, segundo grandes regiões e unidades da federação selecionadas nos períodos 1998-2000, 2001-2003, 2003-2005 e 2006-2008

\begin{tabular}{|c|c|c|c|c|c|c|c|c|}
\hline \multicolumn{9}{|c|}{ Firmas com Gastos em P\&D/ Total de Firmas } \\
\hline & \multicolumn{2}{|c|}{ 1998-2000 } & \multicolumn{2}{|c|}{$2001-2003$} & \multicolumn{2}{|c|}{$2003-2005$} & \multicolumn{2}{|c|}{ 2006-2008 } \\
\hline Brasil & $10,29 \%$ & & $\mathbf{5 , 8 6 \%}$ & & $5,54 \%$ & & $4,25 \%$ & \\
\hline Amazonas & $16,04 \%$ & 1 & $9,55 \%$ & 1 & $8,71 \%$ & 1 & $4,52 \%$ & 7 \\
\hline Pará & $4,35 \%$ & 12 & $4,16 \%$ & 7 & $1,22 \%$ & 12 & $0,74 \%$ & 12 \\
\hline Ceará & $12,26 \%$ & 5 & $1,54 \%$ & 13 & $4,34 \%$ & 8 & $1,20 \%$ & 11 \\
\hline Pernambuco & $10,00 \%$ & 7 & $2,36 \%$ & 12 & $2,58 \%$ & 10 & $6,50 \%$ & 1 \\
\hline Bahia & $5,94 \%$ & 10 & $3,11 \%$ & 9 & $4,97 \%$ & 5 & $1,74 \%$ & 10 \\
\hline Minas Gerais & $6,87 \%$ & 9 & $4,08 \%$ & 8 & $3,17 \%$ & 9 & $2,99 \%$ & 9 \\
\hline Espírito Santo & $2,94 \%$ & 13 & $2,90 \%$ & 10 & $0,95 \%$ & 13 & $0,34 \%$ & 13 \\
\hline Rio de Janeiro & $10,58 \%$ & 6 & $4,99 \%$ & 6 & $4,66 \%$ & 7 & $5,73 \%$ & 3 \\
\hline São Paulo & $12,68 \%$ & 3 & $7,46 \%$ & 3 & $8,03 \%$ & 2 & $5,30 \%$ & 4 \\
\hline Paraná & $8,78 \%$ & 8 & $5,02 \%$ & 5 & $6,22 \%$ & 4 & $3,94 \%$ & 8 \\
\hline Santa Catarina & $12,42 \%$ & 4 & $6,94 \%$ & 4 & $4,67 \%$ & 6 & $4,81 \%$ & 6 \\
\hline Rio Grande do Sul & $13,01 \%$ & 2 & $8,90 \%$ & 2 & $6,34 \%$ & 3 & $4,88 \%$ & 5 \\
\hline Goiás & $4,37 \%$ & 11 & $2,38 \%$ & 11 & $1,85 \%$ & 11 & $6,02 \%$ & 2 \\
\hline \multicolumn{9}{|c|}{ Gastosem P\&D/ Receita Total } \\
\hline & \multicolumn{2}{|c|}{ 1998-2000 } & \multicolumn{2}{|c|}{$2001-2003$} & \multicolumn{2}{|c|}{$2003-2005$} & \multicolumn{2}{|c|}{ 2006-2008 } \\
\hline Brasil & $0,64 \%$ & & $0,53 \%$ & & $0,57 \%$ & & $0,62 \%$ & \\
\hline Amazonas & $1,01 \%$ & 1 & $0,67 \%$ & 2 & $0,56 \%$ & 3 & $0,43 \%$ & 6 \\
\hline Pará & $0,14 \%$ & 13 & $0,07 \%$ & 13 & $0,07 \%$ & 13 & $0,04 \%$ & 13 \\
\hline Ceará & $0,38 \%$ & 8 & $0,13 \%$ & 11 & $0,31 \%$ & 8 & $0,36 \%$ & 8 \\
\hline Pernambuco & $0,35 \%$ & 9 & $0,11 \%$ & 12 & $0,12 \%$ & 12 & $0,07 \%$ & 12 \\
\hline Bahia & $0,29 \%$ & 12 & $0,22 \%$ & 8 & $0,27 \%$ & 9 & $0,43 \%$ & 5 \\
\hline Minas Gerais & $0,39 \%$ & 7 & $0,35 \%$ & 6 & $0,47 \%$ & 5 & $0,80 \%$ & 1 \\
\hline Espírito Santo & $0,30 \%$ & 11 & $0,19 \%$ & 9 & $0,19 \%$ & 10 & $0,18 \%$ & 11 \\
\hline Rio de Janeiro & $0,68 \%$ & 3 & $0,51 \%$ & 3 & $0,62 \%$ & 2 & $0,69 \%$ & 3 \\
\hline São Paulo & $0,77 \%$ & 2 & $0,72 \%$ & 1 & $0,73 \%$ & 1 & $0,77 \%$ & 2 \\
\hline Paraná & $0,50 \%$ & 6 & $0,47 \%$ & 4 & $0,35 \%$ & 7 & $0,44 \%$ & 4 \\
\hline Santa Catarina & $0,57 \%$ & 5 & $0,32 \%$ & 7 & $0,49 \%$ & 4 & $0,29 \%$ & 10 \\
\hline Rio Grande do Sul & $0,58 \%$ & 4 & $0,40 \%$ & 5 & $0,40 \%$ & 6 & $0,39 \%$ & 7 \\
\hline Goiás & $0,30 \%$ & 10 & $0,15 \%$ & 10 & $0,16 \%$ & 11 & $0,29 \%$ & 9 \\
\hline \multicolumn{9}{|c|}{ Pessoal em P\&D/ Pessoal Total } \\
\hline & \multicolumn{2}{|c|}{ 1998-2000 } & \multicolumn{2}{|c|}{$2001-2003$} & \multicolumn{2}{|c|}{ 2003-2005 } & \multicolumn{2}{|c|}{ 2006-2008 } \\
\hline Brasil & $0,84 \%$ & & $0,72 \%$ & & $0,78 \%$ & & $0,69 \%$ & \\
\hline Amazonas & $1,44 \%$ & 1 & $1,97 \%$ & 1 & $1,10 \%$ & 1 & $0,59 \%$ & 8 \\
\hline Pará & $0,24 \%$ & 13 & $0,15 \%$ & 13 & $0,10 \%$ & 13 & $0,13 \%$ & 12 \\
\hline Ceará & $0,46 \%$ & 10 & $0,23 \%$ & 11 & $0,62 \%$ & 6 & $0,61 \%$ & 5 \\
\hline Pernambuco & $0,37 \%$ & 11 & $0,16 \%$ & 12 & $0,14 \%$ & 12 & $0,09 \%$ & 13 \\
\hline Bahia & $0,64 \%$ & 6 & $0,38 \%$ & 9 & $0,54 \%$ & 8 & $0,34 \%$ & 11 \\
\hline Minas Gerais & $0,60 \%$ & 7 & $0,42 \%$ & 8 & $0,52 \%$ & 9 & $0,60 \%$ & 7 \\
\hline Espírito Santo & $0,58 \%$ & 8 & $0,84 \%$ & 3 & $0,51 \%$ & 10 & $0,47 \%$ & 10 \\
\hline Rio de Janeiro & $0,95 \%$ & 4 & $0,75 \%$ & 5 & $0,95 \%$ & 3 & $0,86 \%$ & 2 \\
\hline São Paulo & $1,07 \%$ & 2 & $0,98 \%$ & 2 & $1,08 \%$ & 2 & $0,86 \%$ & 1 \\
\hline Paraná & $0,55 \%$ & 9 & $0,45 \%$ & 7 & $0,62 \%$ & 7 & $0,58 \%$ & 9 \\
\hline Santa Catarina & $0,76 \%$ & 5 & $0,66 \%$ & 6 & $0,70 \%$ & 4 & $0,60 \%$ & 6 \\
\hline Rio Grande do Sul & $0,97 \%$ & 3 & $0,79 \%$ & 4 & $0,70 \%$ & 5 & $0,84 \%$ & 3 \\
\hline Goiás & $0,34 \%$ & 12 & $0,24 \%$ & 10 & $0,24 \%$ & 11 & $0,70 \%$ & 4 \\
\hline
\end{tabular}

Fonte: PINTEC/IBGE 2000, 2003, 2005 e 2008.

Nota1: Dados para o Rio Grande do Norte deixaram de ser discriminados a partir da segunda edição da pesquisa.

Por outro lado, apesar da posição favorável do estado no tocante aos esforços inovativos consubstanciados em atividades de $\mathrm{P} \& \mathrm{D}$, o mesmo não ocorre quando se considera o total de gastos inovativos. De fato, a Tabela 10 indica que, na última rodada da PINTEC, o estado ocupava a $12^{\mathrm{a}}$ posição (entre treze estados considerados) em 
termos do indicador dado pela intensidade dos gastos inovativos totais em relação à receita total das empresas investigadas pela pesquisa, bem como em termos do indicador dado pelo percentual de empresas com gastos em P\&D em relação ao total de empresas investigadas pela PINTEC.

Tabela 10. Indicadores de Esforços Inovativos das indústrias extrativas e de transformação, segundo grandes regiões e unidades da federação selecionadas nos períodos 1998-2000, 2001-2003, 2003-2005 e 2006-2008

\begin{tabular}{|c|c|c|c|c|c|c|c|c|}
\hline \multicolumn{9}{|c|}{ Firmas com Gastos Inovativos / Total de Firmas } \\
\hline & \multicolumn{2}{|c|}{ 1998-2000 } & \multicolumn{2}{|c|}{$2001-2003$} & \multicolumn{2}{|c|}{ 2003-2005 } & \multicolumn{2}{|c|}{ 2006-2008 } \\
\hline Brasil & $26,62 \%$ & & $24,45 \%$ & & $21,91 \%$ & & $30,49 \%$ & \\
\hline Amazonas & $49,52 \%$ & 1 & $23,04 \%$ & 10 & $35,52 \%$ & 1 & $54,95 \%$ & 1 \\
\hline Pará & $9,73 \%$ & 13 & $25,05 \%$ & 6 & $17,85 \%$ & 10 & $26,19 \%$ & 9 \\
\hline Ceará & $27,20 \%$ & 7 & $25,87 \%$ & 5 & $14,76 \%$ & 13 & $24,28 \%$ & 11 \\
\hline Pernambuco & $30,30 \%$ & 3 & $23,15 \%$ & 8 & $26,73 \%$ & 2 & $26,11 \%$ & 10 \\
\hline Bahia & $23,55 \%$ & 10 & $27,00 \%$ & 4 & $21,68 \%$ & 8 & $28,63 \%$ & 8 \\
\hline Minas Gerais & $23,75 \%$ & 9 & $24,52 \%$ & 7 & $16,31 \%$ & 11 & $33,69 \%$ & 5 \\
\hline Espírito Santo & $19,35 \%$ & 12 & $22,32 \%$ & 11 & $25,20 \%$ & 3 & $23,96 \%$ & 12 \\
\hline Rio de Janeiro & $22,49 \%$ & 11 & $18,36 \%$ & 13 & $15,37 \%$ & 12 & $21,66 \%$ & 13 \\
\hline São Paulo & $27,18 \%$ & 8 & $23,11 \%$ & 9 & $23,88 \%$ & 5 & $29,63 \%$ & 7 \\
\hline Paraná & $27,26 \%$ & 6 & $27,43 \%$ & 3 & $23,22 \%$ & 6 & $33,86 \%$ & 3 \\
\hline Santa Catarina & $32,50 \%$ & 2 & $27,73 \%$ & 2 & $21,97 \%$ & 7 & $31,99 \%$ & 6 \\
\hline Rio Grande do Sul & $29,25 \%$ & 4 & $30,75 \%$ & 1 & $24,40 \%$ & 4 & $36,44 \%$ & 2 \\
\hline Goiás & $27,36 \%$ & 5 & $20,89 \%$ & 12 & $20,12 \%$ & 9 & $33,86 \%$ & 4 \\
\hline \multicolumn{9}{|c|}{ Gastos Inovativos/ Receita Total } \\
\hline & \multicolumn{2}{|c|}{ 1998-2000 } & \multicolumn{2}{|c|}{ 2001-2003 } & \multicolumn{2}{|c|}{ 2003-2005 } & \multicolumn{2}{|c|}{ 2006-2008 } \\
\hline Brasil & $3,84 \%$ & & $2,46 \%$ & & $2,77 \%$ & & $2,54 \%$ & \\
\hline Amazonas & $4,21 \%$ & 5 & $2,73 \%$ & 4 & $3,08 \%$ & 3 & $2,24 \%$ & 8 \\
\hline Pará & $3,17 \%$ & 9 & $2,26 \%$ & 6 & $2,29 \%$ & 8 & $3,01 \%$ & 3 \\
\hline Ceará & $2,72 \%$ & 11 & $3,65 \%$ & 2 & $2,45 \%$ & 7 & $1,81 \%$ & 10 \\
\hline Pernambuco & $5,94 \%$ & 1 & $2,11 \%$ & 8 & $1,76 \%$ & 11 & $2,69 \%$ & 5 \\
\hline Bahia & $2,12 \%$ & 13 & $1,75 \%$ & 11 & $1,43 \%$ & 13 & $2,20 \%$ & 9 \\
\hline Minas Gerais & $4,59 \%$ & 3 & $2,42 \%$ & 5 & $3,16 \%$ & 2 & $3,86 \%$ & 2 \\
\hline Espírito Santo & $4,32 \%$ & 4 & $1,37 \%$ & 12 & $2,73 \%$ & 5 & $0,76 \%$ & 13 \\
\hline Rio de Janeiro & $2,37 \%$ & 12 & $1,33 \%$ & 13 & $1,58 \%$ & 12 & $1,44 \%$ & 12 \\
\hline São Paulo & $4,19 \%$ & 6 & $2,80 \%$ & 3 & $3,42 \%$ & 1 & $2,95 \%$ & 4 \\
\hline Paraná & $5,18 \%$ & 2 & $3,77 \%$ & 1 & $2,48 \%$ & 6 & $2,42 \%$ & 6 \\
\hline Santa Catarina & $3,51 \%$ & 8 & $2,06 \%$ & 9 & $2,16 \%$ & 10 & $1,71 \%$ & 11 \\
\hline Rio Grande do Sul & $3,91 \%$ & 7 & $2,21 \%$ & 7 & $2,18 \%$ & 9 & $2,28 \%$ & 7 \\
\hline Goiás & $3,11 \%$ & 10 & $1,93 \%$ & 10 & $2,99 \%$ & 4 & $4,15 \%$ & 1 \\
\hline
\end{tabular}

Fonte: PINTEC/IBGE 2000, 2003, 2005 e 2008.

Nota1: Dados para o Rio Grande do Norte deixaram de ser discriminados a partir da segunda edição da pesquisa.

Na medida em que se sabe que boa parte da base de empresas inovadoras não realiza gastos formais em $\mathrm{P} \& \mathrm{D}$ e sim outros tipos de gastos inovativos (aquisição externa de $\mathrm{P} \& \mathrm{D}$, aquisição de outros conhecimentos externos, aquisição de máquinas e equipamentos, treinamento, introdução das inovaçõesno mercado e projeto industrial), as evidências sugerem que estes esforços se encontram relativamente pouco difundidos entre as empresas que conformam a estrutura produtiva do Estado do Rio de Janeiro, o 
que reforça a hipótese de que há dificuldades de transferência de conhecimento e tecnologia para o setor produtivo.

\section{Terceiro Bloco: os outputs das atividades de C,T\&I no Rio de Janeiro}

Partindo do entendimento, proporcionado pelas análises do primeiro e do segundo bloco, de que o aparato científico-tecnológico do sistema regional de inovação do Rio de Janeiro ocupa uma posição de destaque no cenário nacional, cabe verificar algumas medidas relativas ao seu desempenho. Podemos destacar que há certa predominância do aparato público federal no financiamento e na influência sobre boa parte dos esforços de pesquisa realizados no estado. Neste sentido, a teoria de SRI argumenta que, na presença de um enfoque dirigista caracterizado pela presença de uma instância centralizada que coordena seus fluxos, podem surgir deficiências decorrentes das dificuldades em fazer com que conhecimento gerado seja adaptado e aplicado às necessidades das empresas da região (Cooke, 1992 e Braczyket al., 1998).

De fato, essa questão abrange aspectos fortemente relacionados ao mérito das interações entre os elementos do sistema de inovação, inerentemente difíceis de caracterizar e avaliar. É possível, porém, considerar duas medidas relevantes para avaliar desdobramentos das atividades do subsistema de geração de conhecimento sobre o sistema produtivo: a evolução da taxa de inovação fornecida pela PINTEC/IBGE e do númerode patentes registradas por residentes no Estado do Rio de Janeiro na condição de proxy.

Foram utilizados dados de patentes por se tratar de uma evidência indireta da atividade tecnológica com dados disponíveis para um longo período (Mancusi, 2000). Compreendemos as limitações do uso de patentes como uma medida da atividade tecnológica de uma região devido à complexidade que envolve a sua estrutura. Distorções podem aparecer quando são feitas comparações entre indústrias, pois as inovações podem ser protegidas de várias maneiras distintas, logo a propensão a patentear pode variar entre setores (Basberg, 1987). Essas distorções, consequentemente, também podem ser detectadas para comparação entre regiões à medida que houver estruturas produtivas qualitativamente diferenciadas e padrões de especialização distintos. 
Para analisar patentes, foi feito um esforço de organização dos dados fornecidos pelo European Patent Office (EPO). Considerando que este banco de dados fornece informações de patentes desagregadas ao nível nacional, a opção para análise regional foi discriminar estes dados segundo a residência dos depositantes das patentes. A hipótese que sustenta essa opção metodológica está no fato de que um agente econômico manifesta a maior parte de sua vida social e econômica em um ambiente embebido em características específicas de uma região.

É certo que, com os avanços nas tecnologias de informação e comunicação, os fluxos mundiais de informação e conhecimento se tornaram mais amplos e acessíveis. No entanto, o peso da dimensão local e regional não perdeu sua relevância, constituindo, ainda, o principal ambiente da manifestação social e econômica de um indivíduo (Bathelt et al., 2003). Portanto, consideramos que selecionar as patentes brasileiras registradas por inventores que residem no Rio de Janeiro é uma boa proxy para as patentes provenientes das atividades do SRI fluminense.

Analisando a evolução do número de patentes registradas por inventores residentes no Rio de Janeiro entre 2000 e 2009, podemos observar uma tendência de crescimento. Enquanto tivemos 20 patentes registradas em 2000, 52 patentes foram registradas por residentes do Rio de Janeiro em 2009, um crescimento de 260\%. A reta de tendência presente no Gráfico 4 ilustra essa evolução.

\section{Gráfico 4. Número de patentes registradas por inventores residentes no Estado do Rio de Janeiro entre 2000 e 2009}

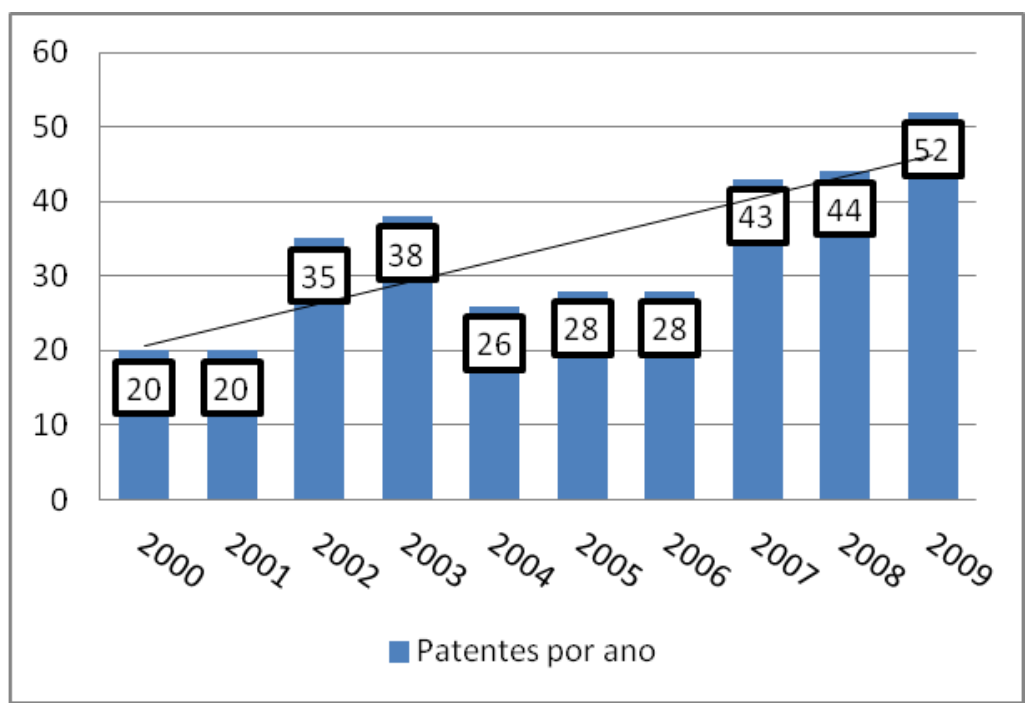

Fonte: Elaboração a partir de dados do EPO. 
Observando os dados apresentados é possível ver um aumento súbito no padrão de patenteamento entre 2001 e 2002. O novo patamar, no entanto, não se firma após 2003, retornando a valores inferiores a 30 patentes por ano entre 2004 e 2006. Após 2007 é interessante notar que houve uma nova quebra na série, colaborando para a tendência positiva.

Organizando uma série com o peso percentual das patentes de residentes no Rio de Janeiro contra patentes de todos os brasileiros, a tendência se inverte, tornandose negativa. As quebras na série são para os mesmos períodos detectados no Gráfico 4, indicando que há uma especificidade na trajetória fluminense com relação à trajetória nacional. Em outras palavras, o fator regional também é importante na determinação da performance da atividade inovativa. Neste sentido, quando se analisa o ritmo de patenteamento, a evidência apresentada aponta na direção contrária daquela evidenciada com relação aos inputs e à base de conhecimento. Mesmo que o Rio de Janeiro ocupe uma posição de destaque no cenário nacional nestes dois quesitos, a tendência de crescimento do número de patentes é inferior à média nacional.

\section{Gráfico 5.Número de patentes registradas por inventores residentes no Brasil entre} 2000 e 2009

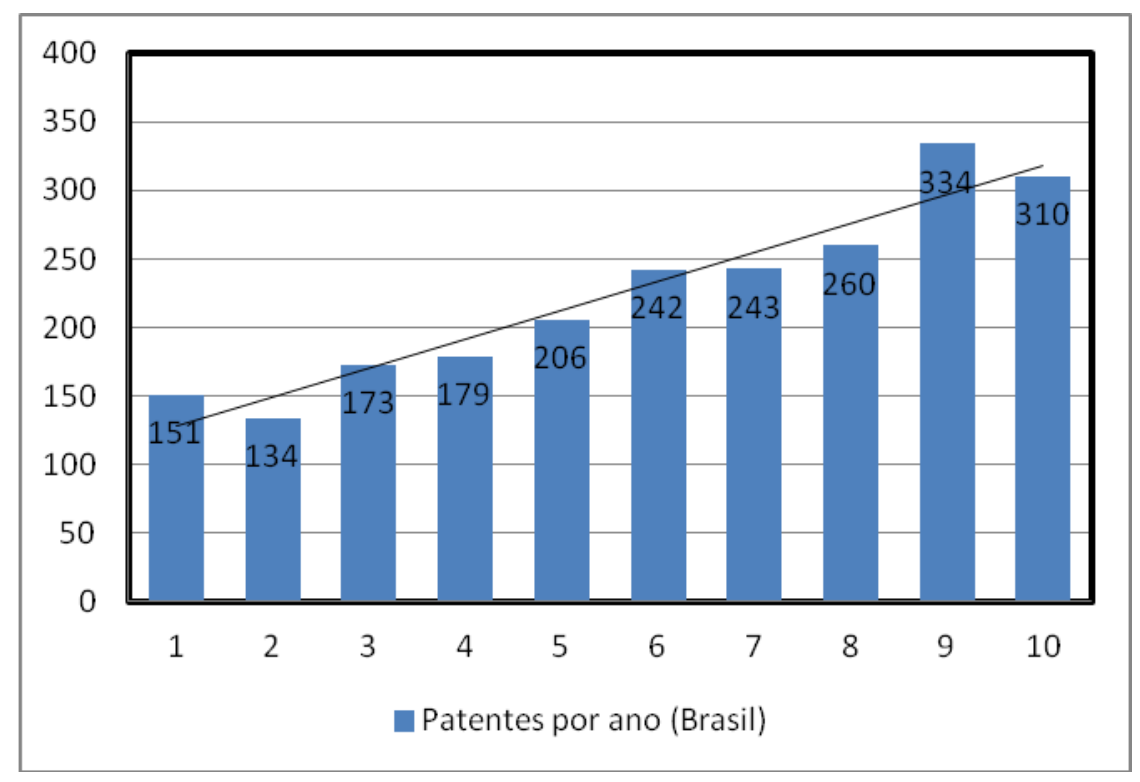

Fonte: Elaboração a partir de dados do EPO. 
Gráfico 6. Peso (\%) relativo das patentes registradas por residentes no Rio de Janeiro no total das patentes registradas por residentes no Brasil entre 2000 e 2009

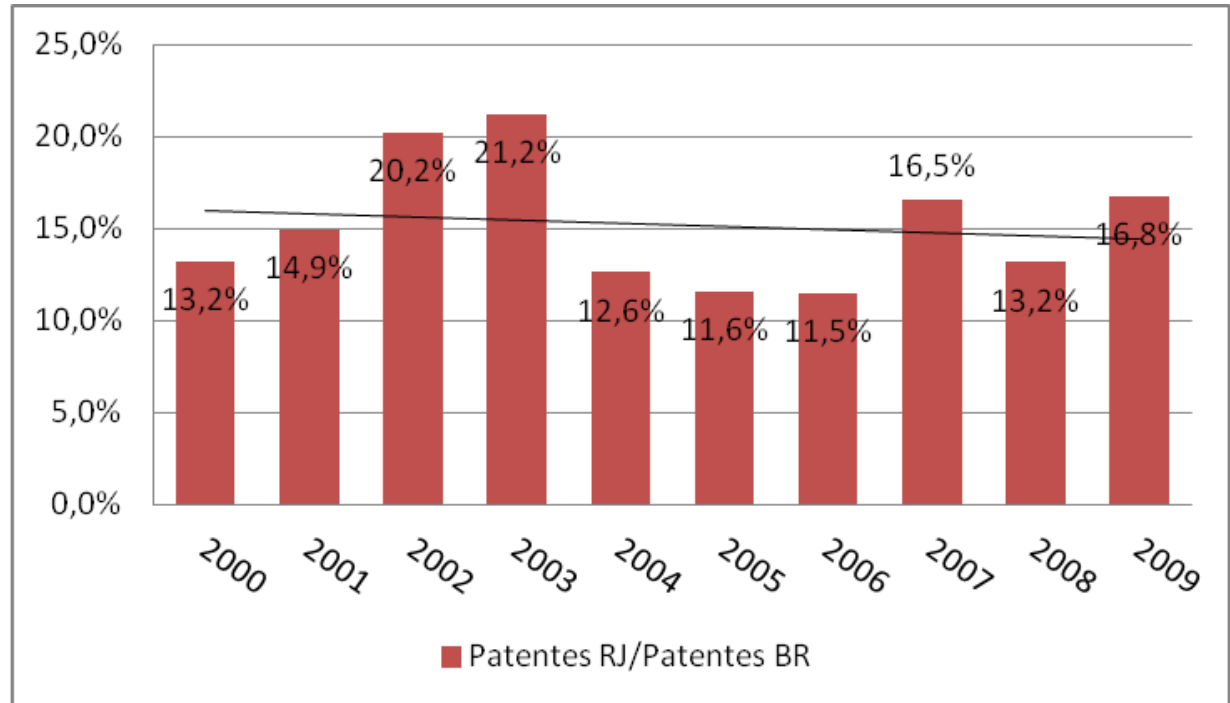

Fonte: Elaboração a partir de dados do EPO.

Assim, em termos do processo de patenteamento, há evidências de uma dinâmica relativamente desfavorável ao Rio de Janeiro. Os dados gerais relativos à performance inovativa mostrados pela PINTEC apontam na mesma direção. De fato, a posição de destaque ocupada pelo Rio de Janeiro em termos do número absoluto de firmas inovadoras não se sustenta quando é avaliada a taxa de inovação. Esta taxa é calculada a partir da razão entre o número de empresas industriais que implementaram inovações de produto e/ou processo e o número total de empresas em uma unidade da federação.

Certamente as informações para alguns estados superam as expectativas. Os casos amazonense e paraense, por exemplo, surpreendem tanto pela volatilidade das taxas como pela dimensão do resultado amazonense. Deve-se levar em consideração que são os estados com as menores amostras, seja em número absoluto de empresas, seja em diversificação setorial. De toda ordem, os dados para as outras unidades da federação, por advirem de amostras maiores, superando as mil empresas,são mais confiáveis.

De uma maneira geral, podemos observar que houve um avanço no desempenho fluminense no período recente. A taxa de inovação do estado, segundo dados da PINTEC, saltou de um patamar entre 25,0\% e 26,0\% nos anos entre 1998 e 
2005 para 32,9\%. Essa melhora em termos absolutos, porém, não é particularmente significativa quando comparada com o conjunto dos estados analisados.

Ordenando um ranking para as unidades da federação cujas empresas integram a amostra da pesquisa, o Rio de Janeiro, em todos os períodos, figura entre a $11^{\mathrm{a}}$ e a $13^{\mathrm{a}}$ colocação dos treze estados selecionados pelo IBGE. Desse modo, evidencia-se o resultado relativamente fraco apresentado pelo Rio de Janeiro em termos de taxa de inovação. Sob este aspecto, podemos perceber que o Rio de Janeiro, embora tenha uma forte base de competência e marcante presença de um aparato de ciência e tecnologia, não vem traduzindo esse diferencial em uma vantagem relativa sobre outras regiões brasileiras. Pelo contrário, a performance das atividades inovativas no território fluminense dá sinais de estar abaixo da média nacional.

\section{Tabela 11. Taxa de Inovação das indústrias extrativas e de transformação, segundo grandes regiões e unidades da federação selecionadas nos períodos 1998-2000, 2001-2003, 2003-2005 e 2006-2008}

\begin{tabular}{|c|c|c|c|c|c|c|c|c|}
\hline \multirow{2}{*}{$\begin{array}{c}\text { Grandes Regiões } \\
\text { e Unidades da } \\
\text { Federação } \\
\text { selecionadas }\end{array}$} & \multicolumn{2}{|c|}{ 1998-2000 } & \multicolumn{2}{|c|}{ 2001-2003 } & \multicolumn{2}{|c|}{ 2003-2005 } & \multicolumn{2}{|c|}{ 2006-2008 } \\
\hline & $\begin{array}{c}\text { Taxa de } \\
\text { Inovação }\end{array}$ & Ranking & $\begin{array}{l}\text { Taxa de } \\
\text { Inovação }\end{array}$ & Ranking & $\begin{array}{c}\text { Taxa de } \\
\text { Inovação }\end{array}$ & Ranking & $\begin{array}{l}\text { Taxa de } \\
\text { Inovação }\end{array}$ & Ranking \\
\hline Brasil & $31,5 \%$ & - & $33,3 \%$ & - & $33,4 \%$ & - & $38,1 \%$ & - \\
\hline Amazonas & $52,6 \%$ & 1 & $38,4 \%$ & 2 & $50,6 \%$ & 1 & $60,9 \%$ & 1 \\
\hline Rio Grande do Sul & $33,5 \%$ & 5 & $39,9 \%$ & 1 & $36,5 \%$ & 5 & $44,1 \%$ & 2 \\
\hline Paraná & $31,3 \%$ & 8 & $36,9 \%$ & 3 & $40,5 \%$ & 2 & $42,7 \%$ & 3 \\
\hline Minas Gerais & $27,8 \%$ & 10 & $34,9 \%$ & 6 & $29,5 \%$ & 9 & $41,4 \%$ & 4 \\
\hline Ceará & $34,7 \%$ & 3 & $33,8 \%$ & 8 & $26,1 \%$ & 12 & $40,3 \%$ & 5 \\
\hline Goiás & $33,2 \%$ & 6 & $33,2 \%$ & 10 & $26,8 \%$ & 11 & $38,2 \%$ & 6 \\
\hline Santa Catarina & $38,8 \%$ & 2 & $35,9 \%$ & 5 & $34,9 \%$ & 6 & $37,9 \%$ & 7 \\
\hline Bahia & $30,7 \%$ & 9 & $33,2 \%$ & 9 & $28,8 \%$ & 10 & $36,5 \%$ & 8 \\
\hline São Paulo & $32,6 \%$ & 7 & $31,1 \%$ & 11 & $33,6 \%$ & 8 & $36,4 \%$ & 9 \\
\hline Espírito Santo & $23,7 \%$ & 12 & $36,3 \%$ & 4 & $37,7 \%$ & 3 & $35,6 \%$ & 10 \\
\hline Rio de Janeiro & $26,0 \%$ & 11 & $25,0 \%$ & 13 & $25,7 \%$ & 13 & $32,9 \%$ & 11 \\
\hline Pernambuco & $34,4 \%$ & 4 & $29,0 \%$ & 12 & $36,8 \%$ & 4 & $31,5 \%$ & 12 \\
\hline Pará & $16,7 \%$ & 13 & $34,2 \%$ & 7 & $34,0 \%$ & 7 & $27,4 \%$ & 13 \\
\hline
\end{tabular}

Fonte: PINTEC/IBGE 2000, 2003, 2005 e 2008.

Nota1: Dados para o Rio Grande do Norte deixaram de ser discriminados a partir da segunda edição da pesquisa.

Nota2: As informações para o agregado da região Sudeste para o período de 1998 a 2000 foi divulgado excluindo-se São Paulo. Optamos por não computá-lo na tabela.

\section{Considerações finais}

A proposta deste estudo é fornecer evidências preliminares a respeito do SRI fluminense. Desse modo, procurou-se considerar as principais fontes de recursos para 
atividades de C,T\&I, a base de competências sobre a qual esses recursos incidem e as alternativas para medir o desempenho em termos de inovação.

$\mathrm{Na}$ discussão desses aspectos, foram levantadas informações a respeito do fluxo de patentes fluminenses, comparando a participação da iniciativa regional e da iniciativa federal no financiamento de atividades de pesquisa e formação de recursos humanos qualificados no Estado do Rio de Janeiro, avaliando-sea base de competências estadual e, finalmente, fazendo a formulação de algumas hipóteses a respeito da configuração do SRI estudado.

A partir da análise realizada no Bloco 1, foi possível constatar que o Rio de Janeiro ocupa uma posição de destaque no financiamento federal às ICTs. Essa característica se articula ao passado de capital federal na atual cidade do Rio e à consequente presença de importantes instituições nacionaisem seu território e em municípios próximos. A presença de organismos de peso como FIOCRUZ, CBPF e Laboratório Nacional de Computação Científica (LNCC), por exemplo, corroboram essa ideia.

Mesmo considerando a posição positiva do estado na absorção desses recursos, observa-se uma tendência à desconcentração espacial do gasto público federal no financiamento à pesquisa e na concessão de bolsas de estudo CAPES e CNPq. Esse processo de dispersão do gasto pelo território nacional, provavelmente, faz parte de uma estratégiade combate à desigualdade social e regional no país. Esse cenário, portanto, deve ser compreendido pelo governo estadual no sentido de mobilizar os instrumentos de política competentes no sentido de compensar essa redução de participação relativa e de tentar manter a liderança, ao lado de São Paulo, em ciência e tecnologia no país.

Justamente com relação à iniciativa regional no financiamento, foi possível verificar que o estado cumpre um papel secundário no financiamento às atividades de C\&T. No entanto, à medida que a iniciativa federal tem estratégias e prioridades que, por vezes, são alheias ou conflitantes aos interesses da economia regional, entendemos que ampliar a participação de organismos como a FAPERJ dentro do SRI fluminense é necessário. De fato, em período recente, mais precisamente na segunda metade da década de 2000, houve um aumento expressivo do volume de recursos da FAPERJ ao pagamento de bolsas e o auxílio à pesquisa e à inovação. Esse aumento tem uma correlação positiva com o desempenho em termos de taxa de inovação e patentes a partir dos anos de 2006 e 2007. Reconhece-se também que essa melhora ainda não é 
suficiente para suplantar o processo de perda relativa e de desconcentração de gastos em favor de outras regiões brasileiras. Portanto, esse processo de fortalecimento da participação do governo estadual deve avançar e se intensificar.

Também é possível ver que o Rio de Janeiro tem uma posição de destaque no cenário nacional quando o quesito é a base de competências, conforme analisado no Bloco 2. Porém o processo de desconcentração espacial mencionado com relação ao financiamento também pode ser percebido quando se consideram os dados relativos ao contingente de doutores titulados nas unidades da federação brasileiras. Mesmo detendo a segunda maior quantidade de doutores empregados, e também de doutores titulados, entre 1996 e 2008, a evolução, em termos percentuais, da economia fluminense fica abaixo da média nacional. Um fato que ameniza essa tendência é o de que essa quantidade de doutores ainda é bastante vasta, em termos absolutos, quando comparada com outros estados brasileiros. É necessário ressaltar, também, que a perda de participação relativa vem sendo mais intensa em São Paulo que no Rio de Janeiro.

Os padrões de especialização da base de competências fluminenses também constituem outro ponto que ameniza a trajetória negativa. É nítido o diferencial da proporção de doutores formados nas áreas de engenharias - reconhecidas por seu potencial de gerar inovações - relativamente a outros estados. A indústria fluminense, principalmente as atividades ligadas ao complexo produtivo do petróleo e gás natural, se beneficia desta situação. Outras áreas identificadas como especializações da base de competências no SRI fluminense estão ligadas às ciências biológicas e à biotecnologia, e às ciências exatas e da natureza, cujos potenciais de complementaridade com outras áreas de conhecimento são grandes.

Devemos entender, porém, que vasto financiamento e uma significativa base de competências especializada em áreas de conhecimento estratégicas não são, per se, capazes de garantir um desempenho tão favorável à inovação no Rio de Janeiro. No Bloco 2 evidenciou-se que, apesar das empresas fluminenses apresentarem uma intensidade de gastos e de pessoal em P\&D relativamente mais alto que a média nacional - o que se explica pela presença de grandes empresas como montantes absolutos desses gastos elevados, como a Petrobras -, o mesmo não ocorre quando se considera a totalidade dos esforços inovativos, o que evidenciaria uma menor disseminação desses esforços pelo conjunto da estrutura produtiva fluminense, o que restringe a capacidade de absorção de conhecimentos gerados pela esfera científica do 
SRI fluminense. Ademais, como foi possível observar na análise do Bloco 3, na década de 2000, a participação das patentes de inventores fluminenses no total das patentes brasileiras apresentou leve tendência à queda.

Outra evidência importante que reforça a percepção de certa debilidade do SRI fluminense pode ser observada quando se consideram as últimas posições ocupadas pelo estado no ranking organizado com a taxa de inovação estimada pelos treze estados selecionados na amostra da Pesquisa de Inovação Tecnológica do IBGE, a PINTEC. Mesmo havendo uma considerável melhora, em termos absolutos, na taxa de inovação fluminense no período entre os anos de 2006 e 2008, a evolução do indicador vis-à-vis a tendência nacional permanece abaixo da média.

O conjunto de dados e evidências analisados neste trabalho, portanto, nos permite supor que o SRI fluminense apresenta deficiências em converter volumosos recursos, humanos e financeiros, em uma performance inovativa compatível. Desse cenário, é possível extrair a hipótese, a ser investigada em maior detalhe, de que o SRI do Rio de Janeiro teria um elo fraco nas interações entre o subsistema de geração de conhecimento e o subsistema de exploração de conhecimento. Essa deficiência, caso confirmada, seria capaz de explicar a contradição constatada, na medida em que dificulta a transmissão de conhecimento e a transferência de tecnologias, tornando o processo inovativo mais árduo e menos efetivo para as empresas integrantes do sistema.

Uma conclusão adicional, sinalizada pela teoria, é que a melhora do desempenho para o SRI estudado, possivelmente, passa pela maior inserção das instituições regionais (como SECT/RJ, FAPERJ, SEDEIS, AGERIO, SEBRAE/RJ, FIRJAN, entre outros) nos processos de financiamento e no estímulo à intensificação das interações e dos fluxos de transferência tecnológica no Rio de Janeiro. Obviamente, essa inserção deve ser precedida de um diagnóstico mais profundo, bem como estar articulada a um arcabouço de planejamento comprometido com um projeto de desenvolvimento mais amplo para a economia fluminense, que leve em conta suas especificidades e potencialidades. 


\section{Referências bibliográficas}

ARANCEGUI, M. N. Los sistemas regionales de innovación.Una revisión crítica.Ekonomiaz, a. 1, v. 70, País Basco, Espanha,2009.

BASBERG, B.Patents and the Measurement of Technological Change: A Survey of the Literature. Research Policy, 16, pp. 131-141, 1987.

BATHELT, H.; MALMBERG, A.; MASKELL, P. Cluster and knowledge: local buzz, global pipelines and the process of knowledge creation.Progress in Human Geography, 28 (1): 31-56, 2003.

BRACZYK, H.; COOKE, P.; HEIDENREICH, M. (eds.).Regional Innovation Systems. London: UCL Press, 1998.

BRITTO, J. N. P.; BITTENCOURT, P. F.; CRUZ , W. M. S. Interação infra-estrutura de Ciência e Tecnologia (C\&T) e setor produtivo no estado do Rio de Janeiro. In: SUZIGAN, W.; ALBUQUERQUE, E. M.; CARIO, S. A. F. (Orgs.). Em Busca da Inovação: interação universidade-empresa no Brasil.Belo Horizonte: Autêntica Editora, 2011.pp. 109-157.

COOKE, P. Regional innovation systems, clustersand the knowledge economy.Industrial and Corporate Change, a. 10, v. 4, pp. 945-974, 2001.

. Regional innovation systems: competitive regulation in the new Europe. GeoForum, v.23, pp. 365-382, 1992.

COOKE, P.; URANGA, M.; ETXEBARRIA, G. Regional Innovation Systems: Institutional and Organizational Dimensions. Research Policy, 26, pp. 475-491, 1997.

DOLOREUX, D. Regional Innovation Systems in Canada: A Comparative Study.Regional Studies, vol. 38, n. 5,pp. 481-494, 2004.

. Regional innovation systems in the periphery: The case of the Beauce in Québec (Canada).International Journal of Innovation Management, vol. 7 n. 1, pp. 67-94, 2003.

DOLOREUX, D.; BITARD, P.; HOMMEN, L. Identifying Regional Innovation Systems in a Globalising Economy: A Plead for an Integrated View.In: II GLOBELICS CONFERENCE,Beijing, China, 2004.

DOLOREUX, D.; PARTO, S. Regional Innovation Systems: A critical synthesis. United NationsUniversity, Institute for New Technologies, Discussion Paper Series 17, Agosto, 2004. 
MANCUSI, M. L.International Technological Specialization in Industrial Countries: Patterns and Dynamics. Sticerd and London School of Economics, 2000.

MARKUSEN, A. Fuzzy Concepts, Scanty Evidence, Policy Distance: The Case for Rigour and Policy Relevance in Critical Regional Studies.Regional Studies, vol. 33, n. 9, pp. 869-884, 1999.

TÖDTLING, F.; TRIPPL, M.One size fits all? Towards a differentiated regional innovation policy approach, Research Policy, 34, pp. 1203-1219, 2005.

VIOTTI, E. B.; IBARRA, A.; OLIVEIRA, C. O.; VIOTTI, R. B. DAHER, S.; VERMULM, R. O emprego dos doutores brasileiros. In: VIOTTI, Eduardo B. (Org.). Brasil 2010:Estudos da demografia da base técnico-científica brasileira. 1. ed.Brasília:Centro de Gestão e Estudos Estratégicos, 2010.v. 1.pp. 181-347. 